\title{
Moored Flux and Dissipation Estimates from the Northern Deepwater Gulf of Mexico
}

\author{
Kurt L. Polzin ${ }^{1, *(\mathbb{D})}$, Binbin Wang $\left.{ }^{2,+} \mathbb{(}\right)$, Zhankun Wang ${ }^{3,4}{ }^{\oplus}$, Fred Thwaites $^{1}$ and Albert J. Williams III ${ }^{1}$ \\ 1 Woods Hole Oceanographic Institution, Woods Hole, MA 02543, USA; fthwaites@whoi.edu (F.T.); \\ swilliams@whoi.edu (A.J.W.III) \\ 2 Geochemical and Environmental Research Group, Texas A\&M University, College Station, TX 77845, USA \\ wangbinb@missouri.edu \\ 3 NOAA's National Centers for Environmental Information, Stennis Space Center, MS 39529, USA; \\ g.zhankunwang@gmail.com \\ 4 Northern Gulf Institute, Mississippi State University, Stennis Space Center, MS 39529, USA \\ * Correspondence: kpolzin@whoi.edu \\ + Current address: Department of Civil and Environmental Engineering, University of Missouri, \\ Columbia, MO 65211, USA.
}

Citation: Polzin, K.L.; Wang, B.; Wang, Z.; Thwaites, F.; Williams, A.J., III. Moored Flux and Dissipation Estimates from the Northern Deepwater Gulf of Mexico. Fluids 2021, 6, 237. https://doi.org/ $10.3390 /$ fluids 6070237

Academic Editors: Joseph J. Kuehl, Pengfei Xue and Fabrice Veron

Received: 20 May 2021

Accepted: 18 June 2021

Published: 30 June 2021

Publisher's Note: MDPI stays neutral with regard to jurisdictional claims in published maps and institutional affiliations.

Copyright: (C) 2021 by the authors Licensee MDPI, Basel, Switzerland. This article is an open access article distributed under the terms and conditions of the Creative Commons Attribution (CC BY) license (https:// creativecommons.org/licenses/by/ $4.0 /)$.

\begin{abstract}
Results from a pilot program to assess boundary mixing processes along the northern continental slope of the Gulf of Mexico are presented. We report a novel attempt to utilize a turbulence flux sensor on a conventional mooring. These data document many of the features expected of a stratified Ekman layer: a buoyancy anomaly over a height less than that of the unstratified Ekman layer and an enhanced turning of the velocity vector with depth. Turbulent stress estimates have an appropriate magnitude and are aligned with the near-bottom velocity vector. However, the Ekman layer is time dependent on inertial-diurnal time scales. Cross slope momentum and temperature fluxes have significant contributions from this frequency band. Collocated turbulent kinetic energy dissipation and temperature variance dissipation estimates imply a dissipation ratio of 0.14 that is not sensibly different from canonical values for shear instability (0.2). This mixing signature is associated with production in the internal wave band rather than frequencies associated with turbulent shear production. Our results reveal that the expectation of a quasi-stationary response to quasi-stationary forcing in the guise of eddy variability is naive and a boundary layer structure that does not support recent theoretical assumptions concerning one-dimensional models of boundary mixing.
\end{abstract}

Keywords: turbulence; mixing; bottom boundary layers; stratified Ekman layer

\section{Introduction}

Direct flux measurements of momentum, temperature, and salinity have been made in boundary layer regimes for decades using stable platforms such as bottom landers [1] or sensors mounted on rigid structures penetrating ice [2]. Such platforms are of limited height in comparison to the oceanic bottom boundary layer, which often exceeds $10 \mathrm{~s}$ of meters in height and the imprint of bottom boundary conditions may exceed $100 \mathrm{~s}$ of meters if internal wave processes are in play. There is thus a compelling need to extend flux measurements much further from the bottom boundary than is possible with bottom landers.

This can potentially be accomplished by placing flux sensors on conventional moorings - a collection of devices connected to a wire and anchored on the sea floor. A fundamental unknown in so doing is potential contamination of the ocean velocity and flux estimates by package motion and effects related to flow distortion from the mooring elements. Here, we report on our attempts to place an acoustic travel time sensor, the Modular Acoustic Velocity Sensor (MAVS [3], Figure 1), on a conventional mooring deployed as part of a project whose goal is to document and understand mixing associated with flow over complex topography on the continental slope in the northern Gulf of Mexico. 


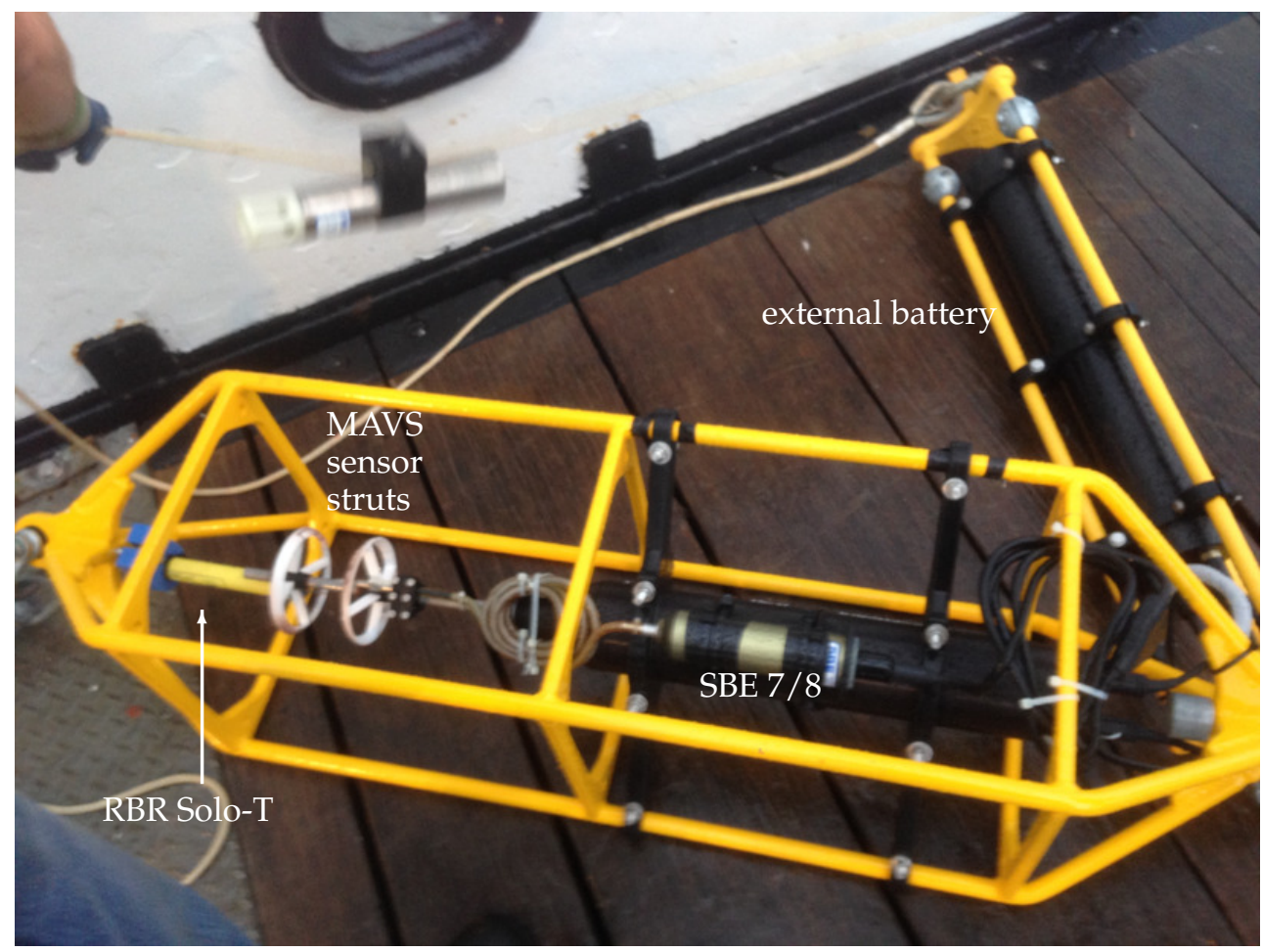

Figure 1. Picture of the enhanced MAVS immediately after recovery. The RBR SoloT temperature sensor is the yellow sensor to the left, the white rings hold the transducer pairs for the MAVS, and the metallic green cylinder is the pressure case for either the SBE-7 or SBE-8 microstructure sensor electronics. An external battery is placed within a second mooring cage in the upper right.

Our experience is that there are no intrinsic limitations to using such enhanced MAVS as flux sensors on conventional moorings relative to their use on bottom landers. This opens up a world of exploration. Caveats, though, abound and further improvements are discussed. This report concerns the geophysical interpretation of data obtained in the first deployment of the prototype, which was tested as part of a boundary mixing experiment along the continental slope of the northern Gulf of Mexico, Figure 2. Moored efforts consisted of short (75 m tall) moorings on the 825 and $600 \mathrm{~m}$ isobaths, which we refer to as 'deep' and 'shallow'. The MAVS prototype was placed at $10 \mathrm{~m}$ height above bottom $\left(H_{\mathrm{ab}}\right)$ on the deep mooring, Figure 3, with sensor details contained in Table 1.

Table 1. Table of sensor depths, sampling intervals, mean temperature and dissipation estimates. Turbulent kinetic energy dissipation rate estimates $(\epsilon)$ in column 6 are derived from (10) and the temperature variance dissipation rates $(\chi)$ are obtained via (11) using those $\epsilon$ estimates. In other columns, dissipation rate estimates use (13) and assume a dissipation ratio $\Gamma=0.2$. The MAVS-RBR $\chi / 2$ is a factor of five smaller than the production band estimate, $1.4 \times 10^{-7} \mathrm{C}^{2} \mathrm{~s}^{-1}$. See text for further details. Estimates are quoted for 2.8 day and 8-day time averages.

\begin{tabular}{|c|c|c|c|c|c|c|c|c|c|}
\hline Sensor & Variables & $\begin{array}{l}H_{\mathrm{ab}} \\
{[\mathrm{m}]}\end{array}$ & $\begin{array}{l}\text { Sampling } \\
\text { Interval [s] }\end{array}$ & $\begin{array}{c}\bar{\theta} \\
{[\mathrm{C}]}\end{array}$ & $\begin{array}{c}\epsilon \& \chi 2.8 \text { Day } \\
{\left[\mathrm{m}^{2} \mathrm{~s}^{-3}\right] \&\left[\mathrm{C}^{2} \mathrm{~s}^{-1}\right]}\end{array}$ & $\begin{array}{l}\epsilon \text { 2.8 Day } \\
{\left[\mathrm{m}^{2} \mathrm{~s}^{-3}\right]}\end{array}$ & $\begin{array}{c}\epsilon 8 \text { Day } \\
{\left[\mathrm{m}^{2} \mathrm{~s}^{-3}\right]}\end{array}$ & $\begin{array}{c}\chi 2.8 \text { Day } \\
{\left[C^{2} \mathrm{~s}^{-1}\right]}\end{array}$ & $\begin{array}{l}\chi 8 \text { Day } \\
{\left[C^{2} \mathrm{~s}^{-1}\right]}\end{array}$ \\
\hline RDCP & $\mathrm{u}, \mathrm{v}, \mathrm{w}$ & (73) & 3600 & & $\mathrm{n} / \mathrm{a}$ & & & & \\
\hline SBE-39 & $\mathrm{T}$ & 60 & 3 & 5.696 & & $1.1 \times 10^{-8}$ & $8.9 \times 10^{-9}$ & $1.4 \times 10^{-8}$ & $1.1 \times 10^{-8}$ \\
\hline SBE-39 & $\mathrm{T}$ & 47 & 3 & 5.631 & & $4.3 \times 10^{-9}$ & $7.9 \times 10^{-9}$ & $5.6 \times 10^{-9}$ & $1.0 \times 10^{-8}$ \\
\hline SBE-39 & $\mathrm{T}$ & 34 & 3 & 5.565 & & $6.8 \times 10^{-9}$ & $2.3 \times 10^{-8}$ & $7.7 \times 10^{-9}$ & $2.5 \times 10^{-8}$ \\
\hline SBE-39 & $\mathrm{T}$ & 13.5 & 3 & 5.473 & & $9.2 \times 10^{-8}$ & $5.6 \times 10^{-8}$ & $7.4 \times 10^{-8}$ & $4.4 \times 10^{-8}$ \\
\hline MAVS & $\mathrm{u}, \mathrm{v}, \mathrm{w}$ & 10 & $1 / 6.25$ & & $\begin{array}{l}1.4 \times 10^{-7}(u) \\
1.1 \times 10^{-7}(v) \\
1.1 \times 10^{-7}(w)\end{array}$ & & & & \\
\hline RBR & $\mathrm{T}$ & 10 & 0.5 & 5.462 & $5.4 \times 10^{-8}$ & $6.4 \times 10^{-8}$ & $2.9 \times 10^{-8}$ & $4.3 \times 10^{-8}$ & $1.9 \times 10^{-8}$ \\
\hline SBE-39 & $\mathrm{T}$ & 8 & 3 & 5.459 & & $3.4 \times 10^{-8}$ & $1.8 \times 10^{-8}$ & $1.5 \times 10^{-8}$ & $7.8 \times 10^{-9}$ \\
\hline
\end{tabular}




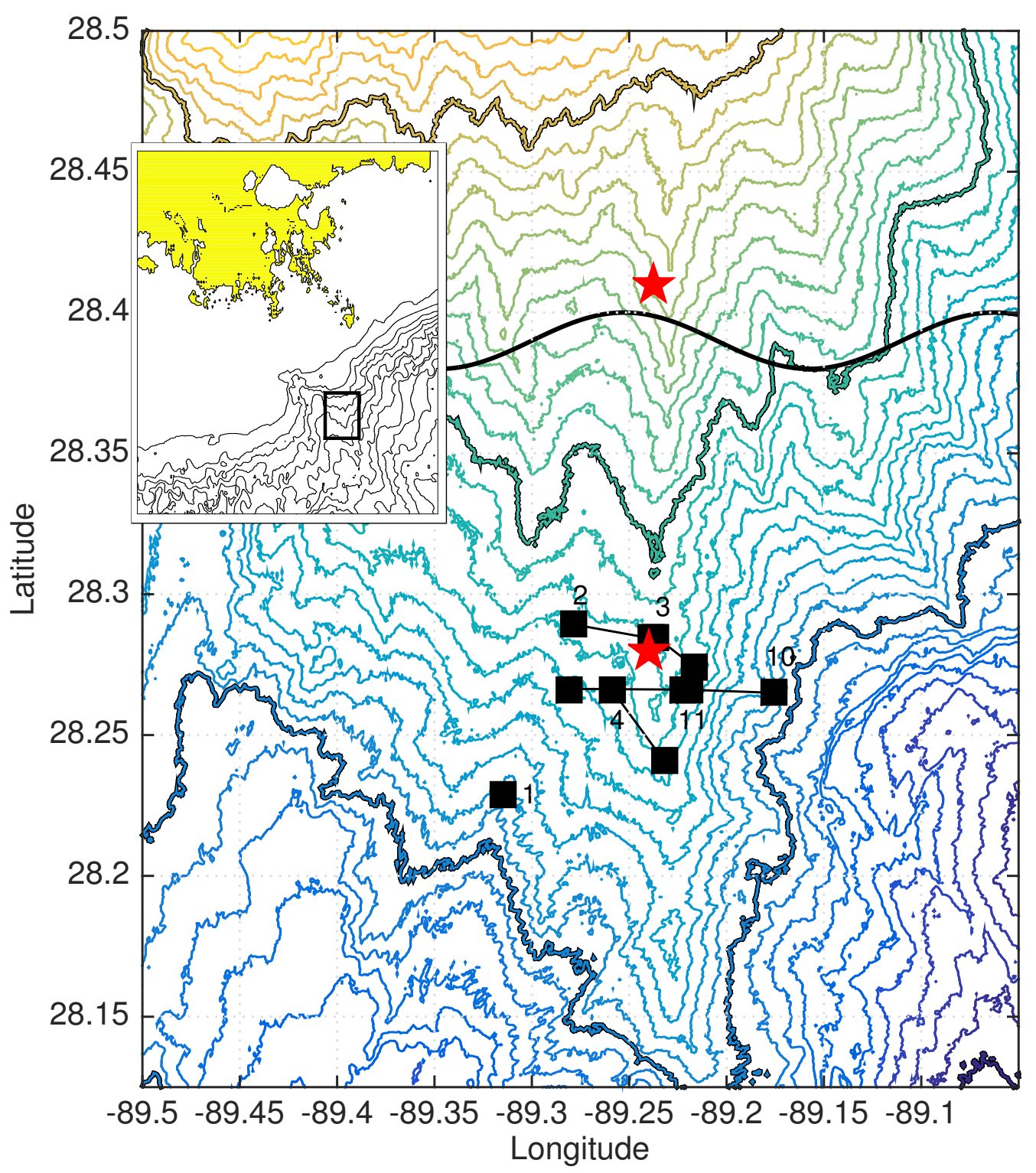

Figure 2. Topography about the deep mooring. Contour intervals are at $25 \mathrm{~m}$ with thick lines denoting the 500, 750, and $1000 \mathrm{~m}$ isobaths. Mooring locations are depicted with red pentagrams. The locations of CTD casts and tow-yos in the vicinity of the deep mooring are depicted with black squares and connecting lines. Numbers correspond to the initial positions of the respective casts/tow-yos. The inset graphic locates the experimental area on the eastern flank of Mississippi Canyon. The solid black trace at the top depicts the horizontal wavelength $\lambda_{h}=2 \pi U / f=18 \mathrm{~km}$ with $U=0.20 \mathrm{~m} \mathrm{~s}^{-1}$.

The need to understand boundary mixing processes in the Gulf of Mexico is placed into perspective by the catastrophic blowout of the Deepwater Horizon oil well, which released about 4 million barrels of oil and $2.5 \times 10^{8}$ standard $\mathrm{m}^{3}$ of natural gas [4,5]. Nearly half of the discharged oil and most of the low molecular weight gases $[4,6]$ formed a prominent plume about $300 \mathrm{~m}$ above the well head [7], which was located at $1522 \mathrm{~m}$ water depth. This study follows and was motivated by a deliberate tracer release experiment [8] directed at documenting linkages between small scale processes and large scale effects at the deep plume level.

That tracer release implied that the estimated diapycnal (cross-isopycnal) dispersion was associated with a boundary enhancement, but the process was not revealed in that study: Gulf of Mexico tides are relatively weak [9] and thus near-boundary mixing associ- 
ated with internal tide generation and dissipation, e.g., Refs. $[10,11]$ is unlikely. There is a notable near-inertial source associated with sea-breeze forcing at diurnal periods [12,13]. Simple ray tracing kinematics suggests, however, that the response to diurnal forcing over the Texas shelf shoots over the top of the northern Deepwater Gulf. This promotes a hypothesis that low frequency flows over the sloping and rough topography of the northern Gulf are the causal agent. From a phenomenological perspective, low frequency currents along the Northern Gulf are dominated by transient eddies associated with Loop Current Eddies, Topographic Rossby Wave variability, and local atmospheric forcing [14-17] rather than time mean flows. Here, we do not concern ourselves with the episodic nature of such flows or how representative the observations are of an ensemble average. Rather, here we attempt to place our observations into a context of understanding how the bottom boundary layer can couple with the internal wavefield over sloping and rough topography.

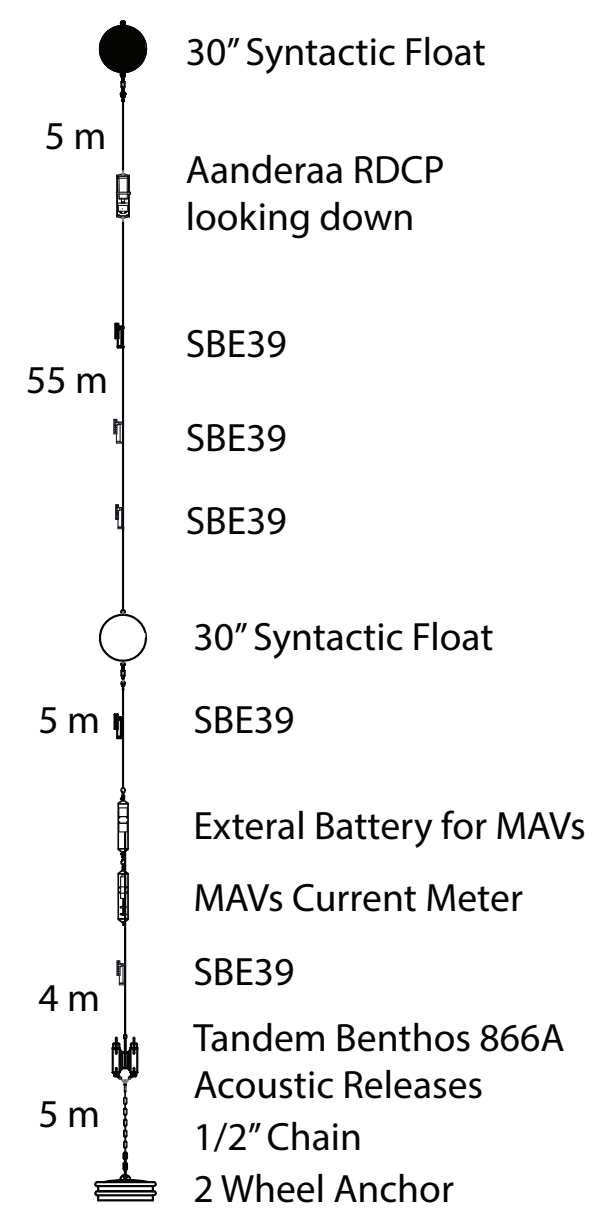

Figure 3. Schematic of the deep mooring.

\subsection{Essential Parameters}

The moored data resolve the time scales of isotropic 3D turbulence, anisotropic stratified turbulence, and wave-like motions. Given this richness, our initial presentation is necessarily detailed to convey the nuances of the coupling between these timescales on the lower frequency flow. We deliver our interpretation by dynamical regime after noting a few basic external parameters:

- Rotation: The Coriolis parameter $f$, conveying the time scale at which rotational effects is important, is $f=6.9 \times 10^{-5} \mathrm{~s}^{-1}$ at the mooring location. Rotation implies a height scale through Ekman layer dynamics and impacts the aspect ratio along which internal wave crests and troughs are aligned via linear internal wave kinematics. 
- Stratification: The buoyancy frequency $N$ represents gravitational forces within a fluid of varying density. Theoretical endeavors refer to an external stratification not influenced by the boundary mixing process. An estimate of this is provided by CTD profiles taken to the south and east of the mooring in slightly deeper water. External to the boundary, stratification at the depth of the MAVS is $N_{\text {ext }} \cong 2.8 \times 10^{-3} \mathrm{~s}^{-1}$. Stratification at the sensor, positioned at $10 \mathrm{~m}$ height above bottom $\left(H_{\mathrm{ab}}=10 \mathrm{~m}\right)$, is smaller, $N_{b d y} \cong 2.0 \times 10^{-3} \mathrm{~s}^{-1}$.

- Topography provides two non-dimensional parameters by itself: the continental slope is $\alpha \cong 1 / 70-1 / 50$ if we take the separation between the 600 and $825 \mathrm{~m}$ isobaths on which the two moorings are located. Topographic roughness with dominant horizontal wavelengths of $\lambda_{h} \sim O(20) \mathrm{km}$ having a zonal orientation is superimposed upon this slope (Figure 2), with similar aspect ratios (slopes) characterizing the roughness in the vicinity of the mooring.

\subsection{Boundary Layers}

Turbulent stresses associated with the viscous condition of no-flow at the bottom boundary result in a hierarchy of boundary layers. The one that concerns us most in this geophysical context is the Ekman layer. Stratification is understood to limit the height to which the turbulent stress can penetrate, e.g., Ref. [18]. For a stably stratified bottom boundary layer over a flat bottom, general formulations for the boundary layer height from Weatherly and Martin [19] and Zilitinkevich and Esau [20] are [18]:

$$
\begin{aligned}
\delta_{\mathrm{WM}} & =A \frac{u_{*}}{f}\left(1+\frac{N_{\text {ext }}^{2}}{f^{2}}\right)^{-1 / 4} \\
\delta_{\mathrm{ZE}} & =0.5 \frac{u_{*}}{f}\left(1+0.15 \frac{N_{\text {ext }}}{f}\right)^{-1 / 2}
\end{aligned}
$$

in which $u_{*}$ is the friction velocity. Weatherly and Martin [19] argue for $A=1.3$ and identify $\delta_{\mathrm{WM}}$ as the depth at which the turbulent kinetic energy becomes zero. The 'height' of the Ekman layer is not uniquely defined: one can alternately use the turning of the velocity vector or velocity magnitude relative to the free stream velocity [21,22]. Moreover, the weakly stratified limit of $\delta_{\mathrm{WM}}$ can be distinguished from the depth of penetration typically assigned to an unstratified fluid, $\delta_{\text {ekman }}=(0.4 \rightarrow 0.5) u_{*} / f$ [23]. The strongly stratified limits both tend to $1.3 / \sqrt{f N}$, slightly smaller than the analytic formulation for the ocean's surface layer from Pollard et al [24], $2^{3 / 4} / \sqrt{f N}$, resulting from a bulk Richardson number closure.

For the intent of interpreting the measurements, we relate $u_{*}$ to a quadratic drag law with drag coefficient $C_{d}$

$$
u_{*}=\sqrt{C_{d} U^{2}},
$$

where $U$ is the velocity in the farfield of the log-layer underlying the Ekman layer. For scaling purposes, we will use $C_{d}=2.5 \times 10^{-3}, U=0.2 \mathrm{~m} \mathrm{~s}^{-1}$ and $N_{\text {ext }} / f=40$ and refer to these as our 'standard parameters'. In Section 4.5, we review our results and consider the consequences of changes to these standard parameters.

In the absence of stratification, the Ekman layer has a nominal height of

$$
\delta_{\text {ekman }}=(0.4 \rightarrow 0.5) u_{*} / f \cong 60 \rightarrow 70 \mathrm{~m}
$$

Using formulae (1), the stratified Ekman scale height clocks in at

$$
\delta_{\text {strat }} \cong 28-30 \mathrm{~m}
$$

A further caveat is that the height scales $\delta_{\text {ekman }}$ and $\delta_{\text {strat }}$ are asymptotic (long time) results for boundary layers over flat topography. Analytics [24] and numerical [25] simulations suggest such states are reached on an e-folding time scale of about half an inertial period. This rapid adjustment is not the case for boundary layers over sloping topography. 
When mean flow is oriented in the same direction as Kelvin wave propagation (i.e., with shallower topography to the right in the Northern Hemisphere), this bottom boundary condition is anticipated to trigger a downslope mass and buoyancy transport in the Ekman layer, leading to a reduction in the near-bottom flow and a decrease in drag (a steady-state paradigm known as the arrested Ekman layer [26,27]). In this steady-state paradigm, the Ekman layer is horizontally stratified and in thermal wind balance. Assuming the bottom boundary layer is well mixed, simple geometric considerations return the height of the buoyancy anomaly required to reduce the flow to zero [27]. This scale is

$$
\delta_{\text {arrest }}=\frac{U f}{\alpha N_{e x t}^{2}}
$$

in which $\alpha$ is the topographic slope. For our standard parameters, this arrest height scale evaluates as

$$
\delta_{\text {arrest }} \cong 100 \mathrm{~m} \text {. }
$$

This height scale is significantly smaller than more sophisticated approaches to closures for the long-term steady state [25], and the increasing disparity between $\delta_{\text {arrest }}$ and the nominal penetration depths in a stratified Ekman layer $\delta_{\text {strat }}$ deserves further inspection.

The underpinning of the arrested Ekman layer state is shear production associated with the along slope geostrophic flow, which then introduces downslope transport of less dense water distributed over the height scale in which the bed stress $u_{*}$ is deposited. Within this paradigm, the buoyancy flux is supported in association with turbulent production in the along slope direction. The bottom boundary layer height scale grows as approximately $t^{1 / 2}$, analogous with the behavior of buoyant convection supported by a boundary condition, but metered by the downslope transport of buoyancy distributed within the Ekman layer, for times far longer than the stratified Ekman layer transient phase.

Discarded in this explanation of the arrested state is a fast time scale of approximately $f^{-1}$ [26], which, in a one-dimensional slope normal model of the bottom boundary layer, consists of internal wave motions parallel to the topography [25]. The details of the coupling between the boundary layer processes and the internal wave response are not fully understood $[25,28,29]$, but these oscillatory cross-slope motions play a role in communicating statically unstable conditions associated with downslope buoyancy transport in the Ekman layer to the arrest height scale [25]. This represents a direct coupling of the internal wavefield with the bottom boundary layer.

\subsection{Internal Waves}

The characterization of the bottom boundary layer in the previous subsection assumes the bottom to either be flat or a planar sloping boundary, leading to a one-dimensional representation. Topographic irregularities represent an intrinsic break in this assumption. Topographic irregularities will impose their horizontal scales on the flow field, introducing a vertical velocity that provides direct coupling with internal waves that potentially leads to significant vertical gradients and mixing. When the amplitude of the topographic variability is small and has length scales permitting the radiation of internal waves, internal lee waves [30] are generated. When the topographic variability is large, however, nearboundary wave breaking, hydraulic like effects, flow separation, and vortex shedding arise and dominate the radiating response, e.g., [31].

In the small amplitude limit of this problem, the internal wave dispersion relation,

$$
\frac{\sqrt{\omega^{2}-f^{2}}}{N}=\frac{k_{h}}{m}
$$

links wave frequency $\omega$ to wave aspect ratio $k_{h} / m$, in which $k_{h}$ is horizontal wavenumber magnitude and $m$ is vertical wavenumber. The quasi-steady limit of this problem, for which the Eulerian frequency $\sigma$ is small, i.e., $\omega=\sigma-\mathbf{k} \cdot \mathbf{U} \cong \mathbf{k} \cdot \mathbf{U}$ with horizontal velocity 
$\mathbf{U}$ and horizontal wavenumber $\mathbf{k}$, gives rise to a well defined height scale and vertical wavelength $\lambda_{v}=2 \pi \delta_{\text {form }}$ of

$$
\delta_{\text {form }}=U / N_{\mathrm{ext}}
$$

in the hydrostatic non-rotating approximation, which evaluates as

$$
\delta_{\text {form }} \cong 70 \mathrm{~m}
$$

As with the Ekman layer on a slope, theory [32] is a bit more complicated with the addition of planar sloping topography. In the quasi-stationary limit, wave crests are aligned with topographic crests, and, if the topographic crests run upslope-downslope, there is a minimum wave aspect ratio and minimum wave frequency[32] at the topographic slope $\alpha$ :

$$
\omega(\alpha) \geq\left(\frac{\alpha^{2} N^{2}}{f^{2}}+1\right)^{1 / 2} f
$$

which evaluates as

$$
\omega(\alpha) \geq 1.18 f
$$

for our standard parameters.

The distinction between 'large' and 'small' amplitude topography is quantified in this context by a steepness parameter

$$
s=N_{e x t} h_{r m s} / U
$$

in which $h_{r m s}$ represents the root-mean-squared topographic perturbation and $\mathrm{U}$ the impinging flow [31]. The steepness parameter can be cast as a ratio between wave aspect ratio $k / m=k U / N$ and rms topographic slope $k h_{r m s}$. Estimates of the steepness parameter were arrived at by spatial filtering of the topography in Figure 2 using Fourier methods and low-order polynomial fits to isolate horizontal wavelengths $k_{h}>f / U$. The estimates indicate $1 / 2<s<1$, implying the potential for finite amplitude effects. Evidence for an internal hydraulic transition slightly upslope of the deep mooring is presented in a companion paper. The interpretation of $s$ is qualified by the addition of a large scale slope and possible complications of rotation.

The rotation of the velocity vector with depth is understood to imply the sense of energy propagation [33]: counterclockwise phase rotation of the horizontal velocity vector implies upward energy propagation in the northern hemisphere. This is in the same sense as the rotation of the velocity vector in a downwelling Ekman layer and thus complicates the interpretation of turning angles associated with turbulent stresses.

\subsection{Instabilities}

A downwelling Ekman layer presents a sink of potential vorticity and the opportunity for anomalously signed potential vorticity at the bottom boundary [34]. In a parallel shear flow without boundaries, such anomalously signed potential vorticity is unconditionally unstable [35] to a class of instabilities that arise in the presence of rotation. It is further understood that the arrested state over uniform sloping topography is unstable to such dynamics [36]. The applicability of potential vorticity dynamics to the observations presented below is speculative. What we see may well arise from forcing related to departures from that planar sloping boundary (i.e., roughness) and external forcing (e.g., by tides) that do not map well onto the boundary conditions assumed for simplified instability calculations.

\subsection{Organization}

This paper is organized as follows: instrumentation and methods are presented in Section 2. The data are presented as time series in Section 3.1 and the vertical structure is discussed in Section 3.2. Section 3.3 presents the high frequency MAVS and thermistor data as spectra along with inertial subrange interpretations of turbulent dissipation and mixing. 
Section 3.4 presents and interprets a co-spectral analysis, largely focused upon the MAVS sensor, in which production regimes and inertial subranges are identified. We discuss our findings in Section 4.

\section{Materials and Methods}

We deployed two moorings at the work site, one at roughly $825 \mathrm{~m}$ and one at $600 \mathrm{~m}$ water depth. These moorings both had a downward looking Aanderaa RDCP at about $75 \mathrm{~m}$ above bottom and 5 SBE-39s with nominal spacing of about $10-15 \mathrm{~m}$. The deeper mooring additionally had an enhanced MAVS at about $10 \mathrm{~m} H_{\mathrm{ab}}$ and was outfitted to record analog data being streamed from SBE-7/8 microstructure temperature/conductivity sensors. There was also an RBR-Solo temperature sensor inserted into the sampling volume of the MAVS acoustic travel time sensor. This RBR was internally recording. We will focus on the turbulence measurements from the deep mooring in this study. These moored sensors are discussed in Section 2.1 and methods for their interpretation presented in Section 2.2. Sensor details and statistics are tabulated in Tables 1 and 2.

Table 2. Table of momentum: mean $(u, v, w)$ and $\left(\overline{u^{\prime} w^{\prime}}, \overline{v^{\prime} w^{\prime}}\right)$. Turbulent production band estimates utilize $\sigma>1 \times 10^{-4} \mathrm{~s}^{-1}$. Internal swash band fluxes are in parentheses () and employ $\sigma<1 \times 10^{-4} \mathrm{~s}^{-1}$.

\begin{tabular}{cccccc}
\hline Sensor & $\mathbf{U}\left[\mathbf{m ~ s}^{-\mathbf{1}}\right]$ & $\mathbf{V}\left[\mathbf{m ~ s}^{-\mathbf{1}}\right]$ & $\mathbf{W}\left[\mathbf{m ~ s}^{-\mathbf{1}}\right]$ & $\boldsymbol{u}^{\prime} \boldsymbol{w}^{\prime}\left[\mathbf{m}^{\mathbf{2}} \mathbf{s}^{-\mathbf{2}}\right]$ & $\boldsymbol{v}^{\prime} \boldsymbol{w}^{\prime}\left[\mathbf{m}^{\mathbf{2}} \mathbf{s}^{-\mathbf{2}}\right]$ \\
\hline RDCP 8.0 day & -0.185 & 0.009 & -0.018 & $\mathrm{n} / \mathrm{a}$ & $\mathrm{n} / \mathrm{a}$ \\
RDCP 2.8 day & -0.189 & 0.003 & -0.017 & $\mathrm{n} / \mathrm{a}$ & $\mathrm{n} / \mathrm{a}$ \\
MAVS 2.8 day & -0.17 & -0.12 & -0.019 & $3.9 \times 10^{-5}$ & $2.6 \times 10^{-5}$ \\
& & & & $\left(0.2 \times 10^{-5}\right)$ & $\left(6 \times 10^{-5}\right)$ \\
\hline
\end{tabular}

\subsection{Moored Sensors}

\subsubsection{Modular Acoustic Velocity Sensor (MAVS)}

The insight motivating this effort is that the intrinsic resolution of the MAVS is $0.3 \mathrm{~mm} / \mathrm{s}$, significantly smaller than the single ping uncertainty associated with Doppler technology with greatly reduced energy costs at that single ping level. Noise sources for the MAVS are understood to be dominated by motion related to strumming of the mooring cable and vortex shedding from the sensor support structures [37]. Both cable and sensor supports have similar dimensions and hence similar Strouhal frequencies, implying contaminations at $6-8 \mathrm{~Hz}$ at relative flow speeds of $0.2 \mathrm{~m} \mathrm{~s}^{-1}$. This implies spatial scales via Taylor's frozen field hypothesis that are similar to, or smaller than, the $10 \mathrm{~cm}$ spatial scale of the MAVS sampling volume and, arguably, are well removed from the spatial scales that characterize turbulent production. A model of the sensor response is presented in [38]. Sufficiently rapid sampling will eliminate aliasing of this noise from within the production and inertial subrange regions of interest. Such rapid sampling required increased memory and battery capacity that was (incompletely) implemented here. Issues of package motion, such as contamination of the tilt measurements by horizontal accelerations, were addressed by augmenting the nominal tilt sensor and compass with a VN100 motion package. The instrument is pictured in Figure 1.

The MAVS was set to run as fast as possible by turning off the compass and using the $\mathrm{VN}-100$ s magnetometer for heading data. This resulted in a roughly $6.25 \mathrm{~Hz}$ sample rate for 4096 samples. The effects of package motion related to mooring strumming were aliased at this sampling rate. Data gaps between files of roughly $3 \mathrm{~s}$ were taken care of by linear interpolation. Time base syncing with the other sensors was accomplished by assuming that the MAVS clock drift was negligible and aligning the records during mooring deployment. The MAVS data record is only 2.8 days of the 9-day deployment. The memory filled up because an extra small memory card was unintentionally inserted. Hardware limits at this data density are $O(100)$ days. Additionally, the VN-100 motion package was mounted upside down and backwards. This was corrected by mapping the velocities onto the coordinate system of the motion package, making corrections for package motion, then mapping the velocities back to the nominal instrument coordinate system. 


\subsubsection{Aanderaa RDCP}

An Aanderaa recording Doppler Current Profiler was placed at $73 \mathrm{~m} H_{\mathrm{ab}}$ on both moorings. Set on low power mode, this sensor was limited to about a $5 \mathrm{~m}$ range. Subsequent usage on a high power mode returned a similarly limited range.

\subsubsection{RBR Solo-T}

A self contained RBR Solo-T temperature logger was mounted such that its sensing element was within the MAVS measurement volume. The protective plastic sensor guard was cut away from the tip to reduce flow obstruction. The manufacturer quotes time constants $\tau_{c}$ of $0.7 \mathrm{~s}$ and $0.1 \mathrm{~s}$ for their two sensor tips, with five times these metrics representing the time for a response after plunging into a cold bath to be within $99 \%$ of the final value. We employed the slower of these and sampled the unit at $2 \mathrm{~Hz}$. This introduces sensor response issues at the highest frequencies that were addressed in the context of a single pole transfer function [39] and simple spectral model for aliasing. The single pole transfer function implies a phase lag of $\pi / 4$ radians at $\sigma \tau_{c}=1$, where $\sigma$ is frequency. The associated phase shifts do not extend to low frequencies that would impact our interpretation of temperature-velocity covariance.

\subsubsection{SBE-39}

Five SBE-39 temperature recorders were placed on the mooring cable at 10-15 m intervals, Table 1 . These were early model SBE-39s with limited memory and duration. They were set to sample at $3 \mathrm{~s}$ intervals and to exhaust available memory over the 10-day deployment. The manufacturer quotes a $0.5 \mathrm{~s}$ time constant in the context of a single pole response function [39]. It was noted that the SBE-39's occasionally pause in their recording of data.

\subsubsection{SeaBird $7 / 8 \mathrm{~s}$}

The MAVS was modified to log analog output from SeaBird 7 and 8 fast response temperature and dual needle conductivity probes that are more commonly used for microstructure applications. The SBE $7 / 8$ analog capture was a nice idea featuring fast response sensors and the ability to match the sampling rate of the MAVS. This scheme did not return useful data.

\subsection{The Turbulent Paradigm}

The basic tools for interpreting the moored data are to (1) identify power laws associated with inertial subranges and ratios between variables and (2) quantify production and fluxes in the context of a Reynolds decomposition of the equations of motion. The Reynolds averaged balance for turbulent kinetic energy (TKE) is

$$
\partial_{t} E+N . L .+\mathcal{P}=\mathcal{B}-\epsilon-\nabla \cdot \overline{u^{\prime} p^{\prime}}
$$

in which $E=\left(u^{\prime 2}+v^{\prime 2}+w^{\prime 2}\right) / 2$ is the turbulent kinetic energy, N.L. are triple correlations and represent nonlinear interactions responsible for transport of energy to smaller scales, production $\mathcal{P}$ corresponds to terms like $\overline{u^{\prime} w^{\prime}} \bar{u}_{z}$, buoyancy flux $\mathcal{B}=-g \rho \overline{w^{\prime} \rho^{\prime}}$ represents work done against gravity in a stratified fluid, $\epsilon$ is the rate of dissipation of turbulence kinetic energy and $\overline{u^{\prime} p^{\prime}}$ represents pressure work. Prime stands for fluctuations and bar is used for the average in our equation notations. Far from boundaries, the expectation [40] is for a production-dissipation balance with buoyancy flux (mixing) being a small (15\%) residual. The situation is not so clear in the presence of a boundary for several reasons. First, flow over non-uniform topography can result in significant flow accelerations and turbulent forcing (Section 1.3) in association with pressure work (form drag). Second, the nonlinear terms N.L. can be cast as the divergence of a spatial flux, and integration over a volume leads to the understanding of the potential transport of turbulent energy $E$ 
within the boundary layer. The Reynolds averaged balance for a scalar such as temperature $\theta$ is:

$$
\frac{1}{2} \frac{\partial \overline{\theta^{\prime 2}}}{\partial t}+\nabla \cdot \overline{u^{\prime} \theta^{\prime 2}}+\overline{u^{\prime} \theta^{\prime}} \cdot \nabla \bar{\theta}=-\frac{\chi}{2}
$$

in which $\nabla \cdot \overline{u^{\prime} \theta^{\prime 2}}$ are nonlinear terms responsible for downscale transport of temperature variance, $\overline{u^{\prime} \theta^{\prime}} \cdot \nabla \bar{\theta}$ are production terms that are similar to the buoyancy flux in the turbulent kinetic energy equation, and $\chi$ is the rate of dissipation of temperature variance. The nominal paradigm is a production-dissipation balance with the vertical production of buoyancy being balanced by dissipation [41]. As with the turbulent kinetic energy equation, the situation is not so clear in the presence of a boundary. A no flux bottom boundary condition requires mean isopycnals to be normal to topography and the boundary region can host significant lateral production in combination with vertical production [42]. As before, a production-dissipation balance can be disrupted by the turbulent transport of temperature variance in the guise of triple correlations [38].

\subsubsection{Inertial Subrange Methods}

In the case of steady spatially local balances, dimensional analysis provides for inertial subranges in which variance is handed over from large spatial scales to smaller spatial scales in a self-similar way that results in spectral power laws in which energy density scales as $\epsilon^{2 / 3} k^{-5 / 3}$, where $k$ is the 3D wavenumber magnitude [43]. Time series recorded by the MAVS do not document 3D wavenumber, but assuming that the small scale turbulence is wafted past the sensor as a frozen field (Taylor's hypothesis), the sensor documents a one-dimensional frequency $\sigma$ spectrum in which $\sigma=k_{1} U$ and $k_{1}$ is the wavenumber in the direction of the low frequency velocity $U$. A more detailed accounting $[38,44]$ returns

$$
\Phi_{i}=\alpha_{i} \varepsilon^{2 / 3} k_{1}^{-5 / 3}
$$

where $i$ refers to the direction of the flow, $\varepsilon$ is the turbulent energy dissipation rate, and $\alpha_{i}$ are the one-dimensional Kolmogorov constants. For streamwise direction $(i=1)$, $\alpha_{1}=1.56 \times 18 / 55$, and $\alpha_{2}=\alpha_{3}=4 \alpha_{1} / 3$ for spanwise $(i=2)$ and vertical $(i=3)$ directions. The factor of 1.56 is an empirically defined prefactor for a three-dimensional wavenumber spectrum, 18/55 accounts for the conversion from a three-dimensional into a one-dimensional wavenumber. The condition of local isotropy [45] distinguishes the spectral levels in streamwise and spanwise directions.

Similarly, the temperature spectrum also has a universal format in the inertial subrange:

$$
\Phi_{\theta}=C_{\theta} \chi \varepsilon^{-1 / 3} k_{1}^{-5 / 3}
$$

in which $C_{\theta}=0.4[38,46]$.

Turbulent dissipation rates $\epsilon$ and $\chi$ can be calculated by fitting the measured spectrum from the MAVS and from the various temperature sensors using (10) and (11). Our method consists of multiplying observed spectra by $\left(k_{1} U\right)^{5 / 3}$ and fitting models that include sensor response, aliasing, and noise discussed in the previous section. Quoted uncertainty estimates are standard errors from that fitting process.

Just as one can define a dissipation ratio $\Gamma_{\mu}$ in the context of diagnosing how production $\mathcal{P}$ could be partitioned between buoyancy flux $\mathcal{B}$ and dissipation $\epsilon$,

$$
\Gamma_{\mu}=\frac{\chi N^{2}}{2 \bar{\theta}_{z}^{2} \epsilon}
$$

one defines a ratio based upon downscale transports $\Gamma_{\text {trans }}$

$$
\Gamma_{\text {trans }}=\frac{\alpha_{i} \Phi_{\theta} N^{2}}{2 C_{\theta} \Phi_{i} \bar{\theta}_{z}^{2}}
$$


and visually identifies this when velocity and normalized temperature spectra are plotted together, i.e.,

$$
\frac{\Phi_{\theta} N^{2}}{\Phi_{i}{\overline{\theta_{z}}}^{2}}=\frac{2 C_{\theta} \Gamma}{\alpha_{i}} \cong 1.18 \Gamma
$$

Thus, for example, if the $w^{\prime}$ and normalized temperature spectra have similar levels,

$$
\Gamma_{\text {trans }} \cong 0.8
$$

If the downscale transports of turbulent kinetic energy and scalar variance are nondivergent, $\Gamma_{\text {trans }}=\Gamma_{\mu}$, i.e., $\Gamma_{\text {trans }}$ is the inertial subrange equivalent of $\Gamma_{\mu}$.

Following Bouruet-Aubertot et al. [47], we can estimate the dissipation rate of TKE and temperature variance from the temperature sensors. The dissipation rate can be estimated:

$$
\varepsilon=\left(\frac{E_{f}}{2 C_{\theta} \Gamma\left(N /\left(g \alpha_{\theta}\right)\right)^{2}}\right)^{3 / 2}
$$

where coefficients $C_{\theta}=0.4, \Gamma=0.2$ and thermal expansion coefficient $\alpha_{\theta}=1.36 \times 10^{-4}{ }^{\circ} \mathrm{C}^{-1}$. Buoyancy frequency $N=\sqrt{g \alpha_{\theta}(d \theta / d z)-g \beta_{\theta}(d S / d z)}$ was estimated from the temperature recorders with the addition of small contributions from salinity $S$ estimated using the $\theta-S$ curve from CTD data obtained from the shipboard survey. The coefficient $E_{f}$ results from fitting $\Phi_{\theta}=E_{f} k_{1}^{-5 / 3}$ using the observed temperature spectrum.

\subsection{Orography}

Topographic variability (orographic variability) on scales of $100 \mathrm{~m}$ to $10 \mathrm{~km}$ is required to characterize the hydrodynamic response. Measurements at a resolution of better than $100 \mathrm{~m}$ are available from multibeam surveys for the northern Gulf from the NOAA National Geophysical Data Center, U.S. Coastal Relief Model, at the website: http:/ /www.ngdc. noaa.gov/mgg/coastal/crm.html (accessed on 1 April 2021).

\section{Results}

\subsection{Time Dependence}

The internal wave paradigm of flow-topography interactions in Section 1.3, whether small or large amplitude topography, is couched in terms of a quasi-stationary response to quasi-stationary (eddy) flow. The observations we obtained provide a different story, one of a time dependent response that we characterize as 'internal swash' in analogy to the surface wave swash zone. Our intent is to allude to similar behavior in direct numerical simulations and large eddy simulations of critical wave reflection and internal tide generation $[48,49]$ in which a wave process trips over itself with shoaling and drag acting in combination. Obvious in the moored time series of temperature (Figure 4) and velocity (Figure 5) are significant contributions from inertial-diurnal frequencies. These inertial-diurnal contributions are most obvious toward the middle of the 8-day record and can be easily distinguished from the wave frequency at the slope aspect ratio (6) by simply counting wave crests and troughs. During the early part of the record, near bottom temperature and N/S currents are characterized by fluctuations having somewhat shorter time scales than those in the middle and toward the end of the time series. Modulation of high frequency turbulence in the near-bottom temperature records (Figure 6) and correlation between cross-slope velocity and temperature (Figure 7) are apparent during the early part of the record as well. 


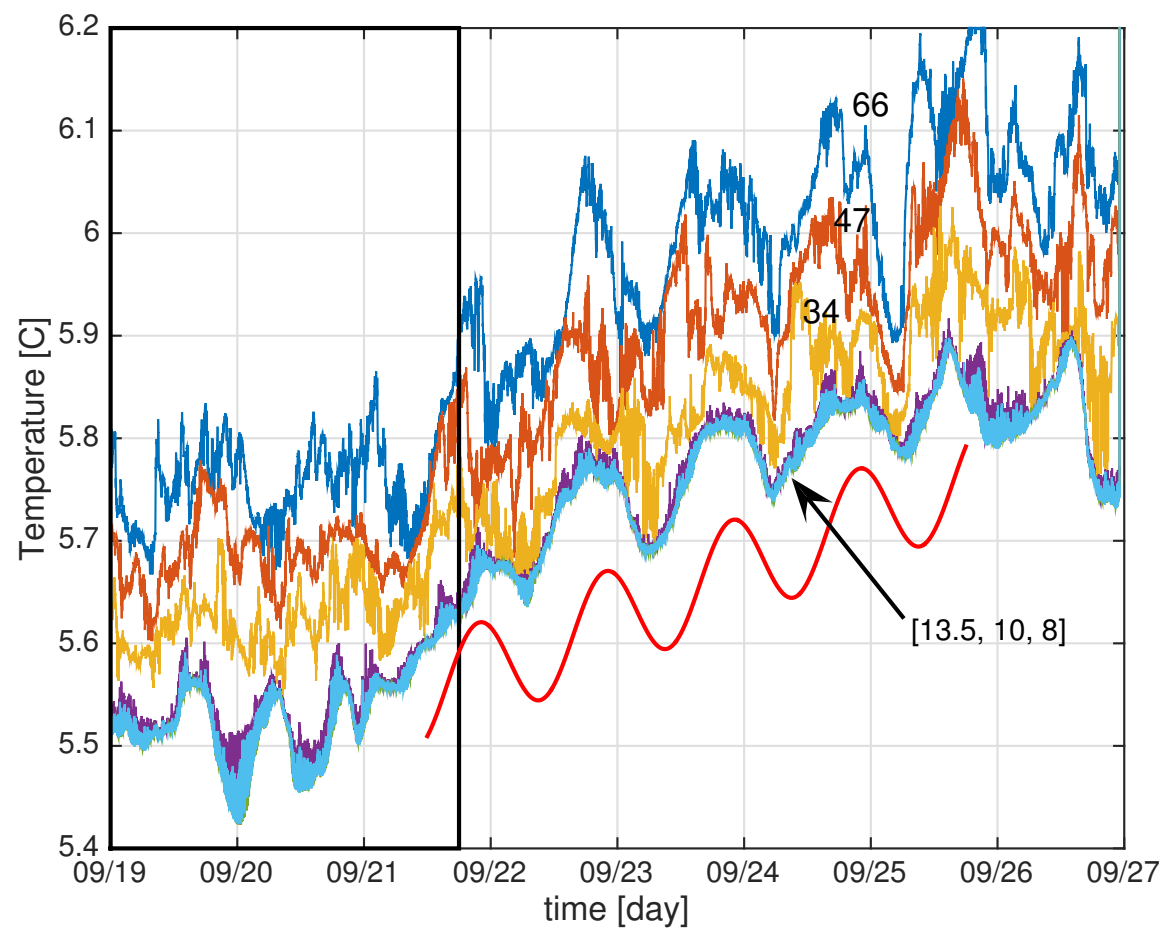

Figure 4. Time series for the $5 \mathrm{SBE}$ and one RBR temperature sensors with $H_{\mathrm{ab}}$ indicated. Inertialdiurnal time scales are rendered as a sine wave in the red trace. These frequencies are distinguishable from the slope parallel frequency (6) as that frequency would have five periods rather than four. The box indicates the time interval of the MAVS record.

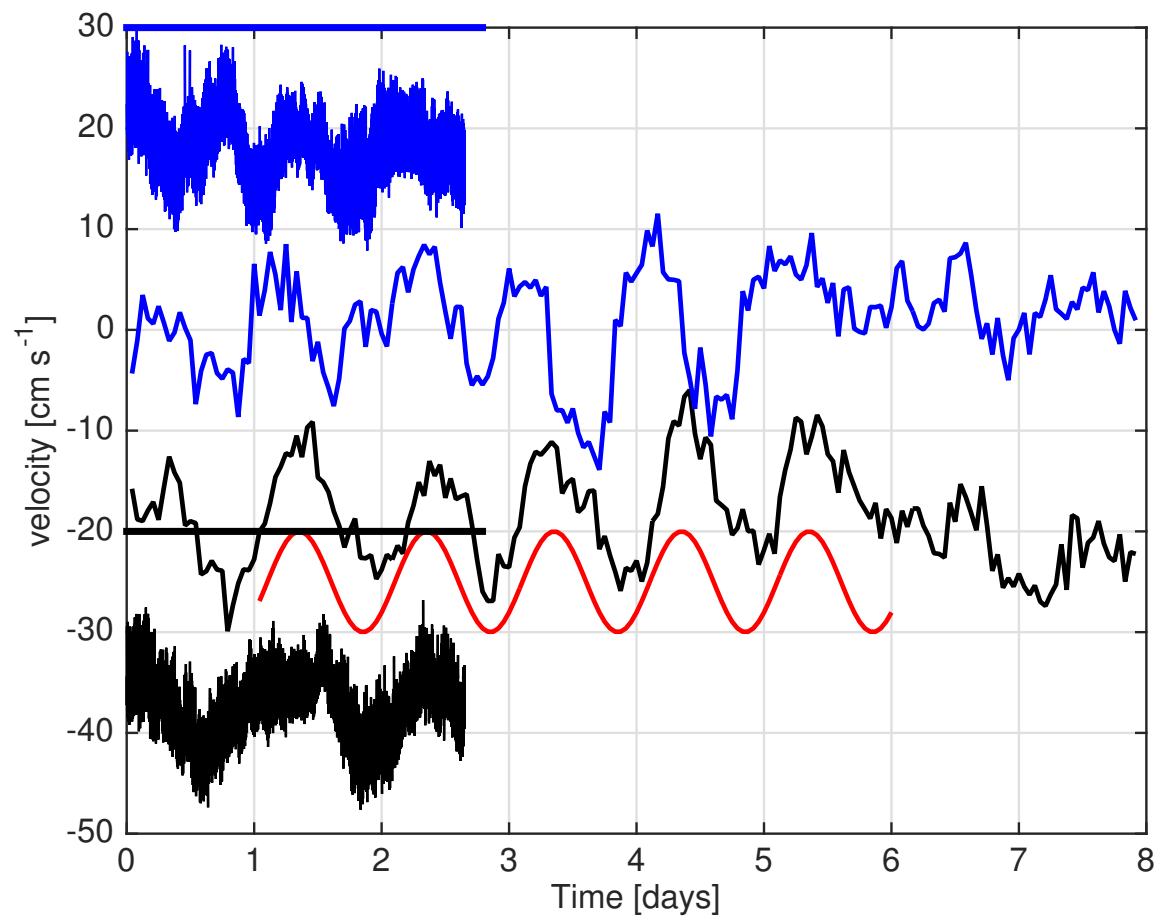

Figure 5. MAVS horizontal velocities at $10 \mathrm{~m} \mathrm{H}_{\mathrm{ab}}$ and superimposed upon the RDCP horizontal velocities at $73 \mathrm{~m} \mathrm{H}_{\mathrm{ab}}$. Blue traces are N/S velocities, black E/W velocities. The MAVS data have been offset (by $+30 \mathrm{~cm} \mathrm{~s}^{-1}$ in N/S and $-20 \mathrm{~cm} \mathrm{~s}^{-1}$ in E/W). Thick lines indicate the zero crossing lines for each MAVS velocity component. Inertial-diurnal time scales are rendered as a sine wave in the red trace. These inertial-diurnal frequencies are distinguishable from the slope parallel frequency (6) as that frequency would have five periods in the space of four inertial periods. 


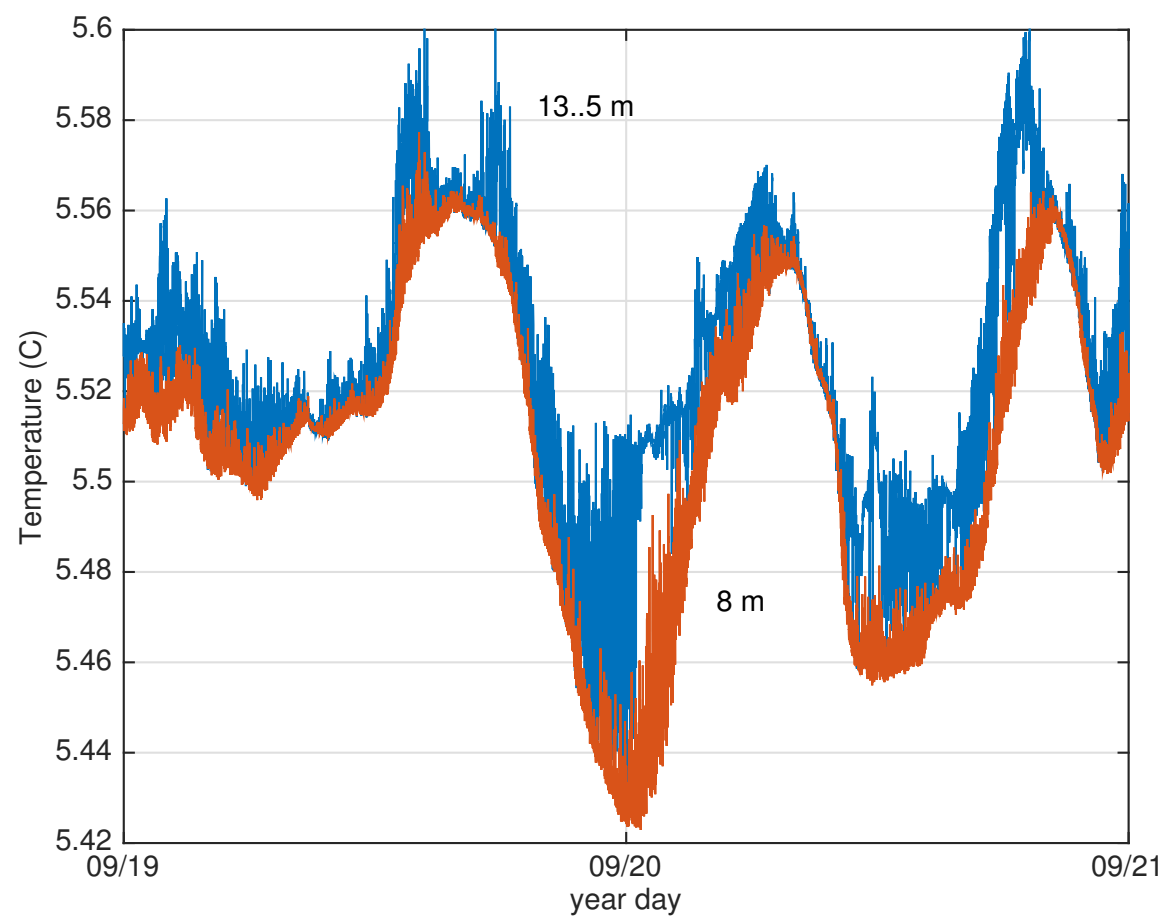

Figure 6. Time series for the bottom 2 SBE temperature sensors. High frequency variability is modulated on internal swash band time scales.

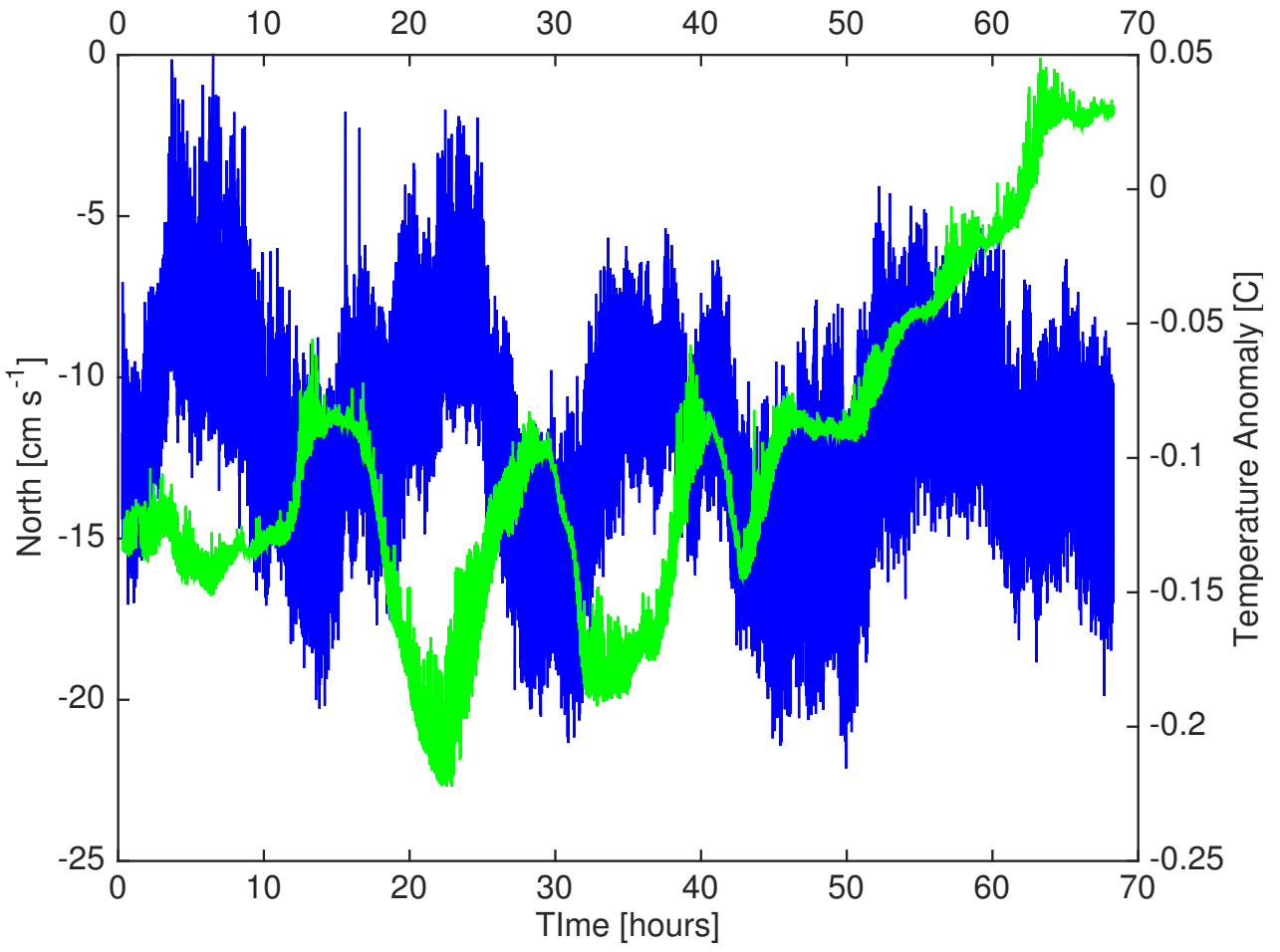

Figure 7. MAVS N/S velocity (blue trace) and RBR temperature (green trace) over the 2.8 day record. The MAVS record has been offset and the temperature record scaled so that the two traces overlay. There is an obvious anti-correlation on internal swash band time scales.

\subsection{Vertical Structure}

Our first objective is to quantify the bottom boundary layer height from stratification estimates in the face of this obvious time dependence. Differencing the time averaged 
estimates of potential temperature from the moored temperature records provides an estimate of $\theta_{z}^{\text {ext }}=0.005 \mathrm{C} / \mathrm{m}$ and a height scale of $10 \mathrm{~m}$ based upon stratification falling to values between $1 / 2$ and $1 / e$ of the external stratification estimate. Shipboard surveys (Figure 8) indicate that the weakly stratified region about the deep mooring has a height scale of approximately $15 \mathrm{~m}$. Both estimates are smaller than the stratified Ekman layer metrics $\delta_{W M}$ and $\delta_{Z E}$ of approximately $30 \mathrm{~m}$. The MAVS sits in a region of abruptly changing stratification, presumably near the top of the bottom boundary layer in which the velocity vector is understood to rotate quickly downslope [18,22].

The turning of the velocity vector between the MAVS (at $10 \mathrm{~m} H_{\mathrm{ab}}$ ) and the RDCP (at $73 \mathrm{~m} \mathrm{Hab}$ ) over the 2.8 day MAVS record is large, Table 1 , approximately $35^{\circ}$, relative to numerical results for a flat bottom [18]. However, it is not inconsistent with our standard parameters. From vertical integration of the along-slope momentum equation, the downslope Ekman transport $T_{\text {ekman }}=u_{*}^{2} / f$. Distributing this transport evenly over a height scale of $10 \mathrm{~m}$ provides a turning angle of $35^{\circ}$ counter-clockwise viewing from above. The issue is that the observed boundary layer height scale is smaller than the asymptotic height scales $\delta_{\mathrm{WM}}$ and $\delta_{\mathrm{ZE}}$ and that characterizing the long-time numerical results.

The interpretation of turning of the velocity vector in association with boundary layer dynamics is not unique. In the context of a quasi-stationary internal lee wave response (Section 1.3), one anticipates a turning of 1 radian over a height scale of $U / N_{\text {ext }}$ in the perturbation velocity field. That wave height scale clocks in as $70 \mathrm{~m}$, implying a $50^{\circ}$ turning over the two current meters in the perturbation fields. Our observations do not speak to what the magnitude of the perturbation field is in the context of a quasi-stationary internal lee wave model: what we observe is a highly time dependent internal wave band response, Figures 4-7.

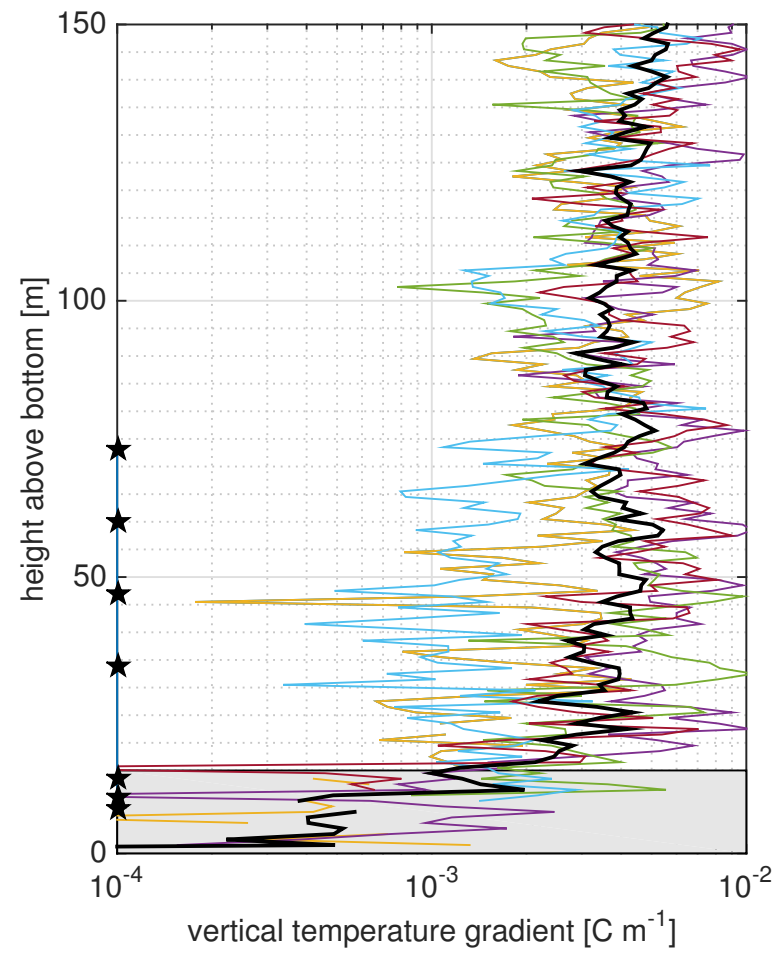

Figure 8. Vertical profiles of potential temperature gradient estimated from CTD tow-yos about the deep mooring, Figure 2. Colored traces represent the mean temperature gradients for 5 tow-yos, the thick black trace represents the mean of those five. The grey shaded region represents the reduced stratification in the bottommost $15 \mathrm{~m}$, smaller than the nominal height scale of the stratified Ekman layer and slightly larger than that documented in the moored sensors. Pentagrams on the left indicate the vertical disposition of the moored instrumentation. Tow-yo sampling extends to $10-15 \mathrm{~m} H_{\mathrm{ab}}$, with $35 \%$ of the casts to within $5 \mathrm{~m}$ of the bottom. 


\subsection{Moored Data as Spectra}

MAVS and RBR Spectra appear in Figure 9, in which the horizontal components have been rotated by $35^{\circ}$ into the record mean current direction. High frequency tails of $u, w$, and $T$ show respectable $-5 / 3$ subrange tails. Velocity spectra exhibit an increasing trend towards the Nyquist frequency which represents either motionally induced noise or the effects of vortex shedding, with potential complications from aliasing and sensor response functions. There are additional bumps in $v$, less prominent in $u$ at frequencies of 0.08 and $0.3 \mathrm{cps}$. Noise in $u$ and $w$ is roughly $3 \mathrm{~mm} / \mathrm{s}$.

Buoyancy Reynolds numbers $\epsilon / v N^{2}$ are sufficiently large, $O\left(10^{4}\right)$ that one can expect the rotated velocity spectra to scale in the ratio $\left(U_{r}: V_{r}: W\right) \sim(1: 4 / 3: 4 / 3)$ [45]. This degree of subtlety is obscured by small noise contributions that vary amongst velocity components. Fits to the observed spectra using the response model of [38] are suggestive of locally isotropic conditions, but lie in between ratios of (1:1:1) and (1:4/3:4/3).

Estimates of both $\epsilon$ and $\chi$ are possible from the MAVS (one for each velocity axis) and co-located RBR sensor using stratification estimates provided by nearby temperature sensors. Fitting inertial subrange formulae returns $\epsilon \cong 1.2 \times 10^{-7} \mathrm{~W} / \mathrm{kg}$ and $\chi \cong 5.4 \times 10^{8} \mathrm{C}^{2} \mathrm{~s}^{-1}$. Their combination implies a transport ratio $\Gamma_{\text {trans }} \cong 0.14$ and diapycnal diffusivity $\Gamma \epsilon / N^{2} \cong 40 \times 10^{-4} \mathrm{~m}^{2} \mathrm{~s}^{-1}$. The estimated dissipation ratio is not appreciably different from that quoted for numerical simulations of shear instability [40] and does not fit with a paradigm of significant reduction in dissipation ratio at the bottom boundary articulated by [50].

Frequency spectra from the temperature recorders placed along the mooring cable fall into two distinct groups delineated by the height above the bottom. Sensors at $(8.0,10.0$ 13.5) $\mathrm{m} H_{\mathrm{ab}}$ have reduced spectral levels within the 'Turbulent Production' frequency range $1 \times 10^{-4}<\sigma<0.02 \mathrm{cps}$. Sensors outside $(34,47,60) \mathrm{m} H_{\mathrm{ab}}$ of what we have identified as the stratified Ekman layer host larger spectral levels in that frequency range. This grouping provides a potential criterion for differentiating boundary layer turbulence within the stratified Ekman layer from wave driven turbulence associated with the coupling of waves to the boundary layer. Further investigation is called for. A vertical profile of dissipation $\epsilon$ is possible from the six temperature recorders on the mooring assuming a dissipation ratio. Here, we use a value of $\Gamma=0.2$. These averaged estimates suggest a maximum just above the current meter $\left(13.5 \mathrm{~m} \mathrm{H} \mathrm{Hb}_{\mathrm{b}}\right)$ and the presence of significant turbulence outside of what we have identified as the stratified Ekman layer, Table 1.

The authors in [51] define a boundary influenced regime in which turbulent length scale suppression in simple association with distance from the boundary potentially suppresses the partitioning of production into the buoyancy flux. Their boundary influenced regime occurs when $H_{\mathrm{ab}}<2 \pi L_{o}$ in which the Ozmidov length scale $L_{o}=\sqrt{\epsilon / N^{3}}$ articulates the length scale at which the inertial forces of turbulence are comparable to those of gravity. Our estimates return $2 \pi L_{o} \cong 20 \mathrm{~m}$ and imply that the MAVS, placed at $10 \mathrm{~m} H_{\mathrm{ab}}$, is within this boundary influenced regime. Our transport ratio compares nicely with those of [51]. 


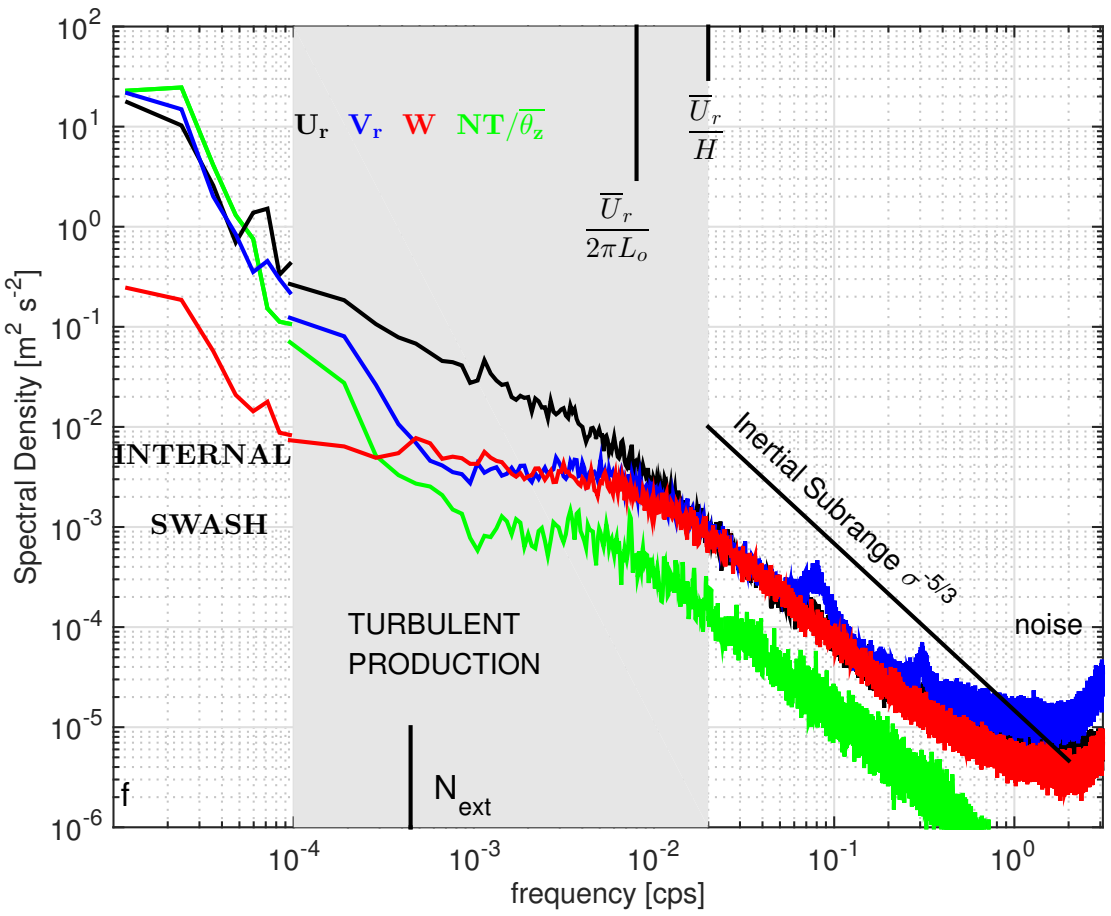

Figure 9. MAVS+RBR spectra over the 2.8 day record. Spectra use two windows. Temperature data have been interpolated onto the MAVS time base and are rendered as potential energy by multiplying the temperature time series by $N / \bar{\theta}_{z}$. See Figure 10 for spectra of the original time series. The frequency scale corresponding to length scale limitations on the inertial subrange $\frac{U}{H_{\mathrm{ab}}}$ is noted. The Ozmidov length $L_{0}$ is a a factor of two larger, indicating that the sensor is within a 'boundary influenced' [51] regime.

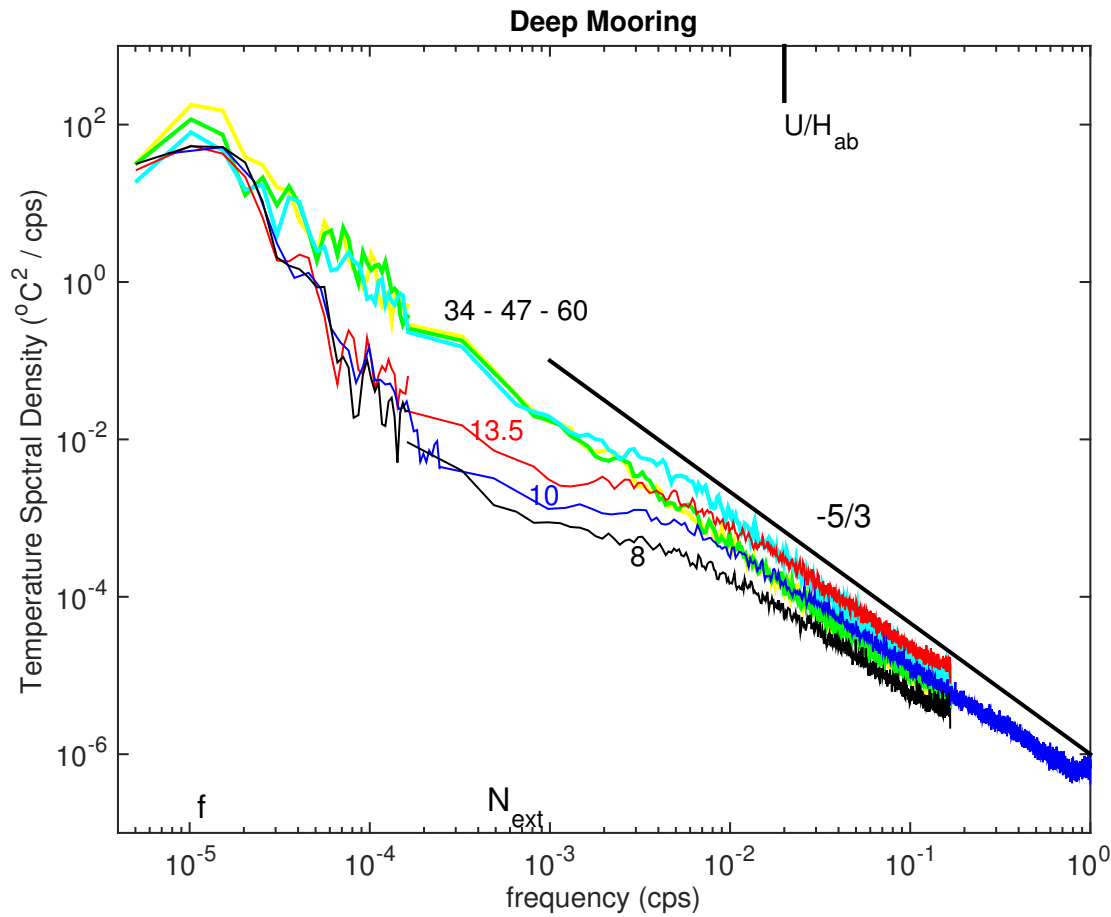

Figure 10. Spectra for the five SBE and one RBR temperature sensors. Spectra are color coded (black, blue, red, cyan, green, yellow) and labeled with their height above bottom coordinate. 


\subsection{Moored Data as Cospectra}

In the atmospheric surface boundary layer, three-dimensional eddies are inefficient at carrying information about the surface stress aloft. From a measurement point at $H_{\mathrm{ab}}$, three-dimensional eddies with vertical wavelength $2 \pi H_{\mathrm{ab}}$ have a similar horizontal wavelength and, via Taylor's frozen field hypothesis, this translates into an apparent frequency $\sigma=U / H_{\mathrm{ab}}$. In the atmospheric boundary layer, frequencies greater than $U / H_{\mathrm{ab}}$ correspond to the inertial subrange and frequencies smaller than $U / H_{\mathrm{ab}}$ are within the production range [52]. Given the standard parameter of $U=0.2 \mathrm{~m} \mathrm{~s}^{-1}$ and $H_{\mathrm{ab}}=10 \mathrm{~m}, \sigma>0.02 \mathrm{~Hz}$ corresponds to the inertial subrange. In the atmospheric surface boundary layer, smaller scale eddies tend to be more efficient at transporting heat than momentum [52] and thus one expects temperature variance production to extend to somewhat higher frequency than $U / H_{\mathrm{ab}}$. Here, we execute cospectral analyses to identify the production regimes in the MAVS record.

\subsubsection{Momentum}

Significant contributions to the Reynolds stress $\overline{u^{\prime} w^{\prime}}$ and $\overline{v^{\prime} w^{\prime}}$ occur where one would anticipate, at frequencies greater than $10 f$ and smaller than the start of the inertial subrange, $U / H_{\mathrm{ab}}$, Figures 11 and 12. In a vector format, these combine to a total of $0.5 \times 10^{-4} \mathrm{~m}^{2} \mathrm{~s}^{-2}$ and are directed anti-parallel to the record averaged current. The magnitude represents a $50 \%$ reduction from the bed stress using our scaling estimates of $C_{d}=2.5 \times 10^{-3}$ and $U_{r}=0.20 \mathrm{~m} \mathrm{~s}^{-1}$. Both direction and magnitude are plausibly consistent with numerical results for the stratified Ekman layer over a flat bottom [18], although the boundary layer height scale is quite a bit smaller than the long time result $\delta_{W M}$ and $\delta_{Z T}$.
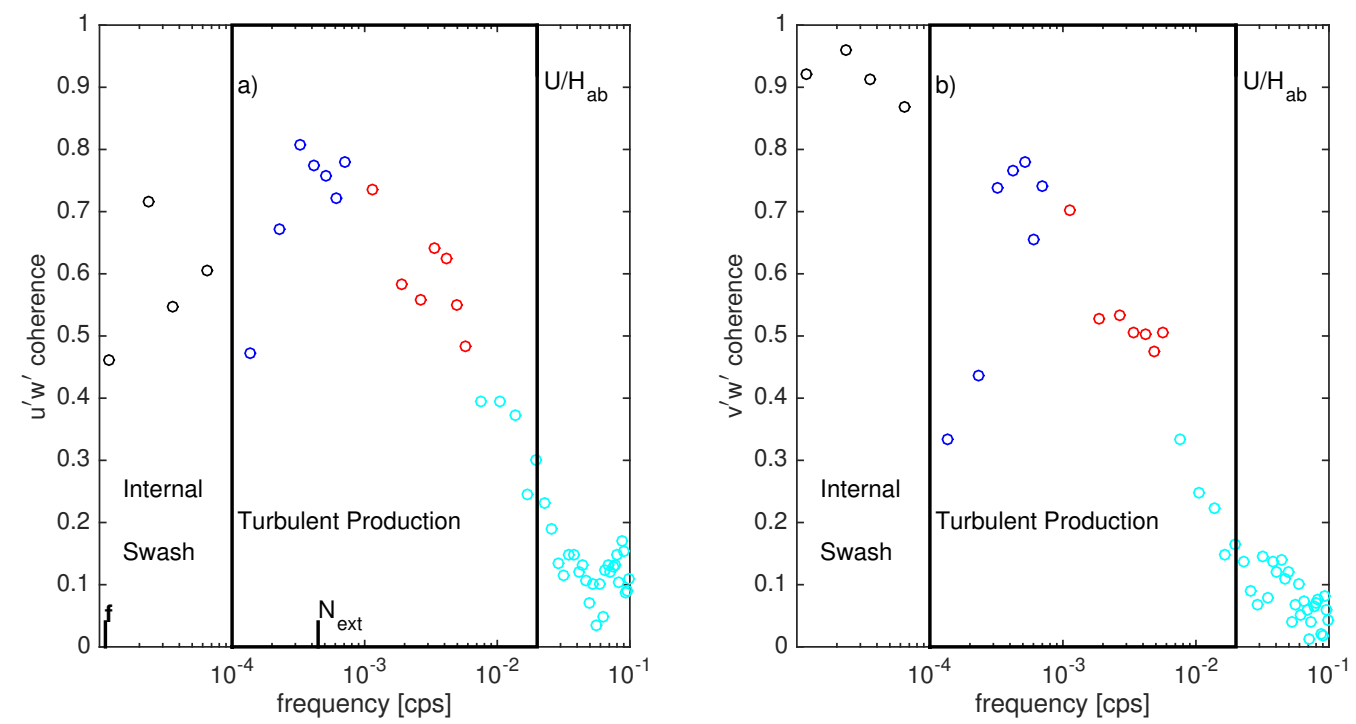

Figure 11. (a) $u^{\prime} w^{\prime}$ and (b) $v^{\prime} w^{\prime}$ coherences. Note the similarities within the 'turbulent production' and higher frequency 'inertial subrange' regimes and the difference within the 'internal swash' regime. The high meridional coherences within the 'internal swash' regime are interpreted as a coupling with internal wave motions directed upslope. 


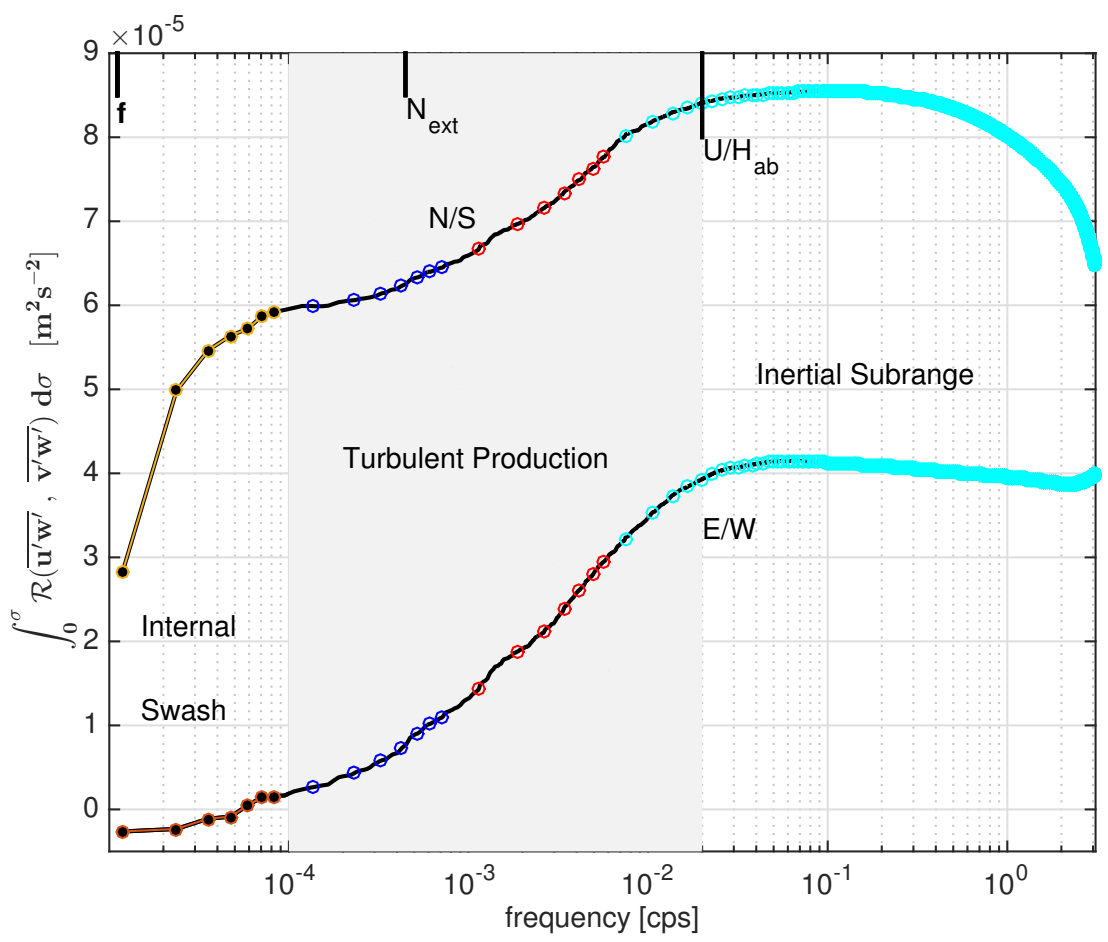

Figure 12. Integrated momentum fluxes. $\tau_{\text {production }}^{x, y}=\left(4 \times 10^{-5}, 2.6 \times 10^{-5}\right) \mathrm{m}^{2} \mathrm{~s}^{-2}$; $\tau_{\text {swash }}^{x, y}=\left(0,6 \times 10^{-5}\right) \mathrm{m}^{2} \mathrm{~s}^{-2}$. Trends of the N/S momentum flux within the inertial subrange region are regarded as an instrumental artifact relating to vortex shedding and/or package motion.

The meridional Reynolds stress contains an even larger contribution of $0.6 \times 10^{-4} \mathrm{~m}^{2} \mathrm{~s}^{-2}$ in a frequency band of $f-10 f$ that we have termed 'Internal Swash'. Worthy of note is that this Reynolds stress is a significant fraction of the bed stress (nominally $1 \times 10^{-4} \mathrm{~m}^{2} \mathrm{~s}^{-2}$ ) and is directed directly up the mean topographic slope. We invoke the 'internal swash's terminology to distinguish behavior in the meridional (cross-slope) and zonal (along-slope) directions. We also find a significant temperature flux in the cross-slope direction (see below) and the 'internal swash' appellation intends to evoke an analogy to a a surface wave swash zone. This notion of 'internal swash' appears in connection with numerical simulations of the critical wave reflection and near-critical internal tide generation $[48,49]$. Here, the data suggest an obvious hypothesis of a dynamical linkage between the downwelling Ekman boundary layer and internal wave radiation. The underlying dynamics are uncertain and deserve further attention.

\subsubsection{Temperature}

The temperature flux falls out of a straightforward spectral calculation, Figure 13, in which the running integral of the real part of the velocity-temperature cospectra are displayed. Beyond taking care that the MAVS and RBR time bases were aligned, the calculation of the temperature flux was 'robust'. While there are few effective degrees of freedom in a time series that is three days long when the covariance is provided by frequencies of $1-2 f$, the results are robust to a variety of computational methodologies. Simply detrending the time series with polynomial fits and integrating the product of the anomaly time series provides estimates that are similar to the cospectral estimates (a factor of two smaller), and this is sufficient to conclude the following:

- Internal swash band fluxes dominate: $\left(\overline{v^{\prime} T^{\prime}}, \overline{w^{\prime} T^{\prime}}\right)=\left(-5 \times 10^{-4},-4 \times 10^{-5}\right) \mathrm{m} \mathrm{s}^{-1} \mathrm{C}$. Due to the limited duration of the record, statistical significance is marginal. A coherence of 0.7 (see Figures 14 and 15) and six degrees of freedom implies a normalized random uncertainty of $60 \%$. The anticorrelation is obvious though (Figure 7). 
- Production range fluxes are more statistically reliable, but much smaller, several percent of the respective swash band metrics. Coherences within the production band (Figure 14) are much smaller than their momentum flux counterparts (Figure 11). Moreover, relative to the mean stratification, production band fluxes are upgradient and imply restratification, Figure 16.

- Inertial subrange fluxes are negligible, as they should be within an inertial subrange.

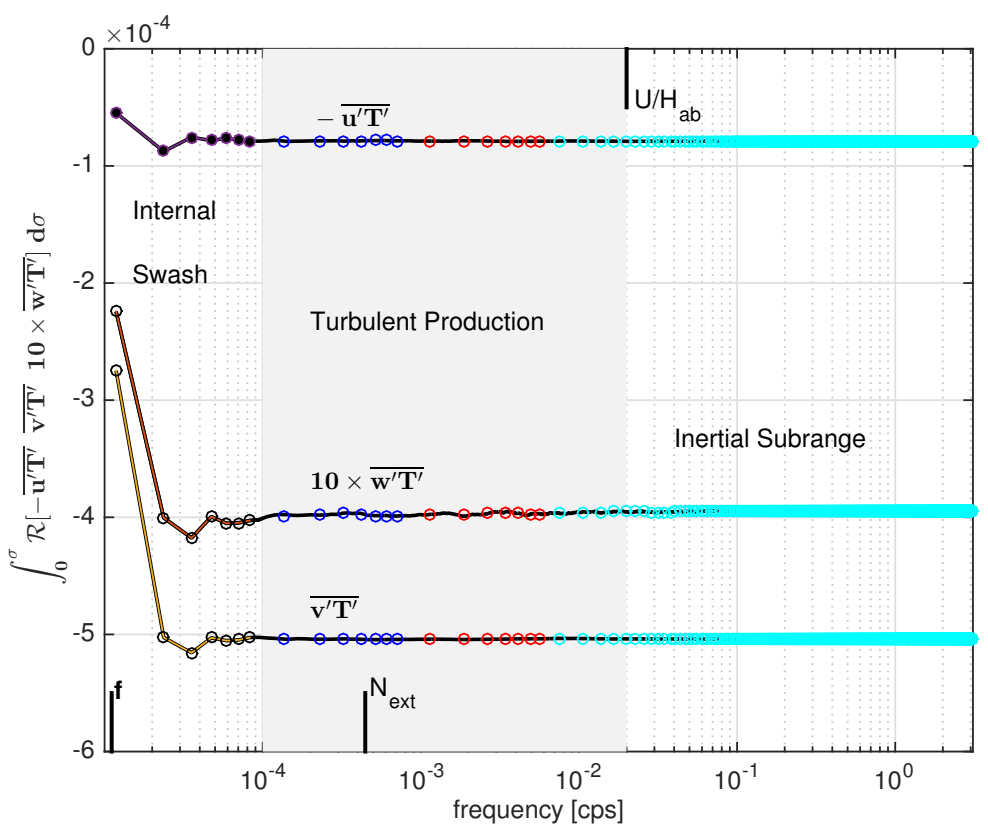

Figure 13. Running integrals of temperature fluxes in three dimensions: $\left(-\Re\left(u^{\prime} T^{\prime}\right) ; \Re\left(v^{\prime} T^{\prime}\right)\right.$; $\left.10 \times \Re\left(w^{\prime} T^{\prime}\right)\right)$.

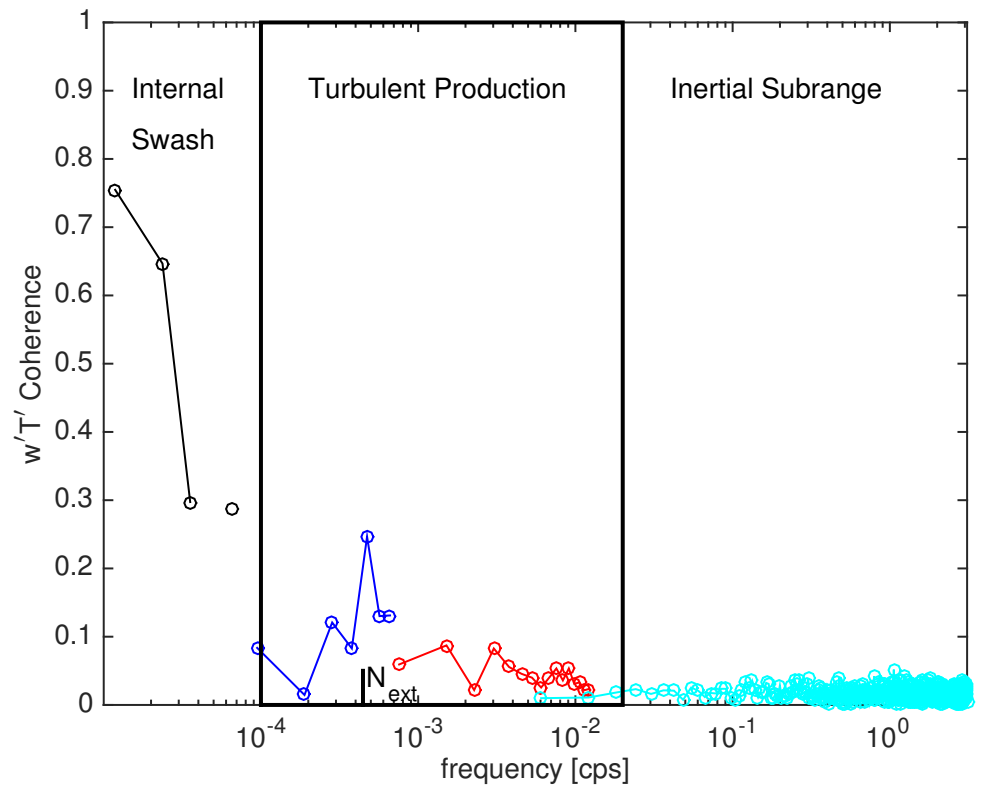

Figure 14. $w^{\prime} T^{\prime}$ coherence. Coherence in the production regime is small, $O(0.05)$. Color coding is associated with increased averaging within the frequency domain. Note that coherences in the production regime in Figure 11 are larger than those for the temperature flux in this figure. 


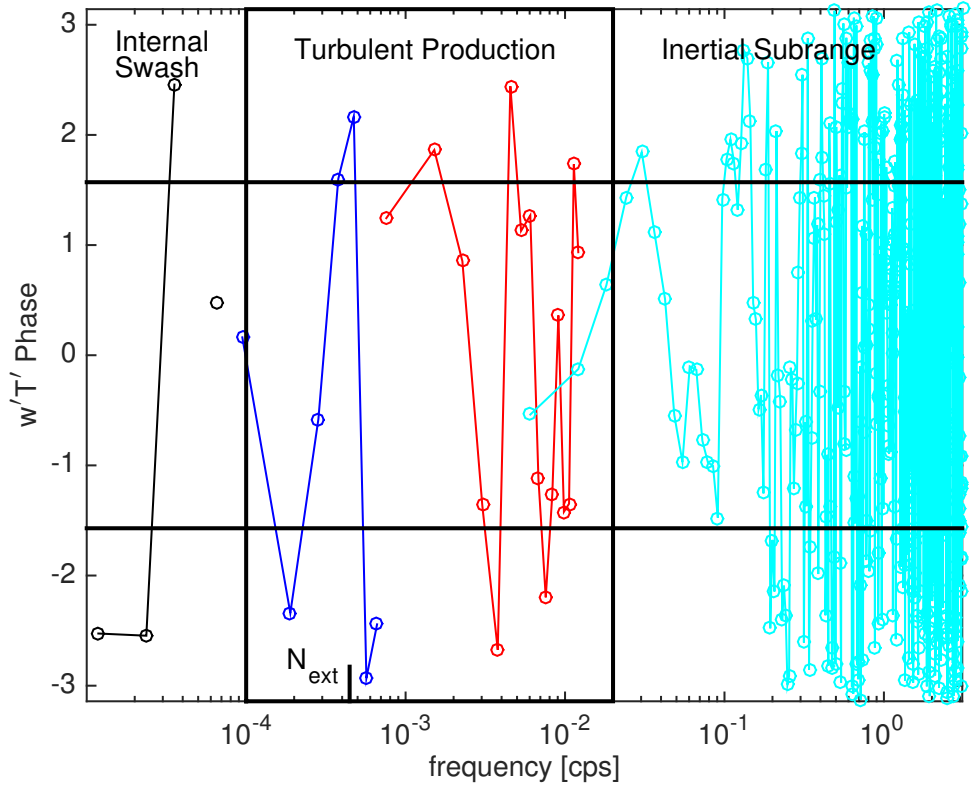

Figure 15. $w^{\prime} T^{\prime}$ phase. Phase in the production regime bounces between $\pm \pi / 2$. Color coding is associated with increased averaging within the frequency domain.

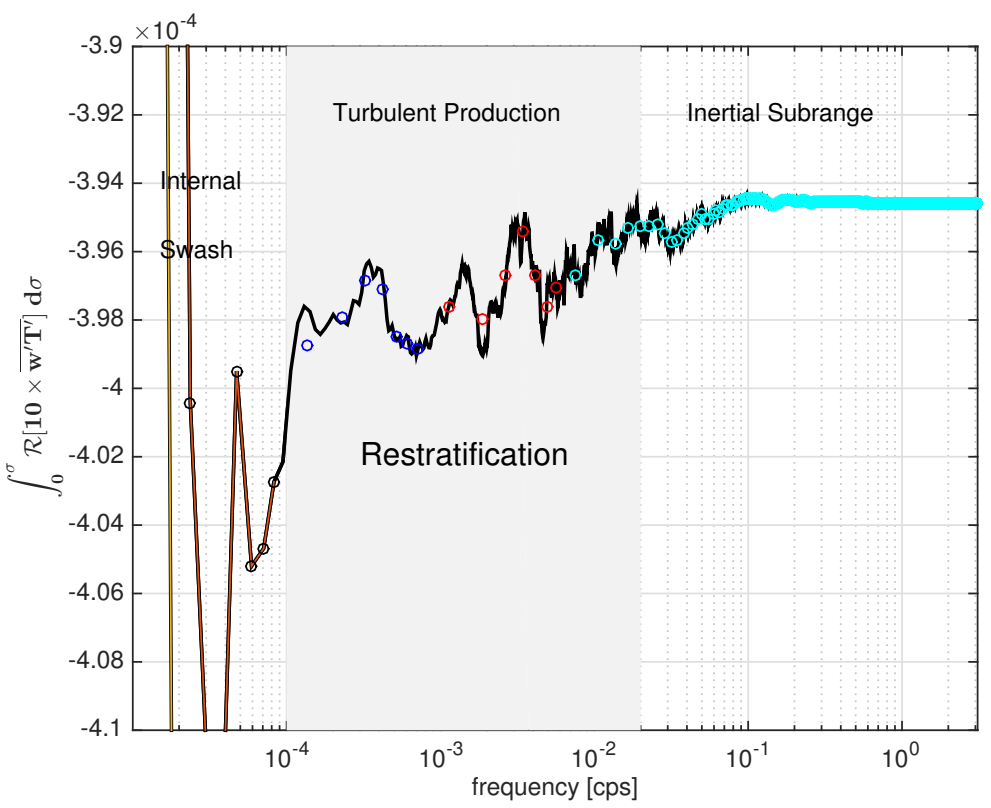

Figure 16. Running integral of the vertical temperature flux from the previous panel, with emphasis on the turbulent production region of frequency space. In this frequency band, the fluxes are upgradient, i.e., restratifying.

\section{Discussion}

Direct flux estimates are the gold standard of turbulence research as they let one directly address budgets. Direct estimates of turbulent momentum fluxes [1,2] and occasionally temperature fluxes [38] have been made for decades from stable platforms such as bottom landers. Here, we placed one such instrument, the MAVS, on a conventional mooring with the express intent of exploring the evolution of the bottom boundary layer to heights greater than is possible on rigid platforms. We have done so over sloping topography. This is a situation in which the intersection of isopycnals with the topography provides for a direct coupling of the boundary layer with internal waves [25] and may also introduce complexities of additional submesoscale dynamics due to the influence of 
rotation [36]. Below, we discuss how the coupling was manifested in the observations and further modifications to enhance the capability of the sensors.

\subsection{Momentum Fluxes}

Interpretation of momentum flux estimates requires some notion of the bottom boundary condition on that flux, i.e., the bed stress. For the purpose of discussion, we use a quadratic drag formulation and the measured current at $10 \mathrm{~m} \mathrm{H}_{\mathrm{ab}}$. The bed stress metric is thus $1 \times 10^{-4} \mathrm{~m}^{2} \mathrm{~s}^{-2}$. There are two distinct frequency bands that contribute to the measured momentum fluxes.

The first frequency band characterized turbulent fluxes between $10 f$ and $U / H_{a b}$, with the upper bound being similar to measurements in the atmospheric surface boundary layer [53]. As expected, this flux is directed anti-parallel to the $10 \mathrm{~m}$ current. The flux is half the magnitude of the nominal bedstress. This decrease from the nominal bedstress is consistent with a boundary layer height scale of approximately $10 \mathrm{~m}$ in both nearby CTD casts (Figure 8 ) and moored temperature sensors. The veering of the velocity vector at $10 \mathrm{~m}$ in comparison to a current meter at $70 \mathrm{~m}$ was $35^{\circ}$ in the downslope direction (Figure 17), again consistent with the nominal bedstress and a $10 \mathrm{~m}$ bottom boundary layer height scale.

The second frequency band contributing to the momentum flux is contained within (1-10) $f$. We refer to this as an internal swash band, in analogy to a surface wave swash zone [48]. This internal swash momentum flux is $60 \%$ of the nominal bedstress and directed upslope, Figure 17. The direction is aligned with coupling of the boundary layer with the internal gravity wavefield in one-dimensional models [25]. The upslope orientation of this flux implicates internal gravity wave dynamics rather than submesoscale instabilities [36], which are aligned at a cross slope orientation of $45^{\circ}$ and for which the fastest growing instabilities have no buoyancy perturbation [54]. Information concerning how the magnitude of this upslope internal swash band momentum flux might depend upon the bed stress and other environmental parameters does not appear in the literature.

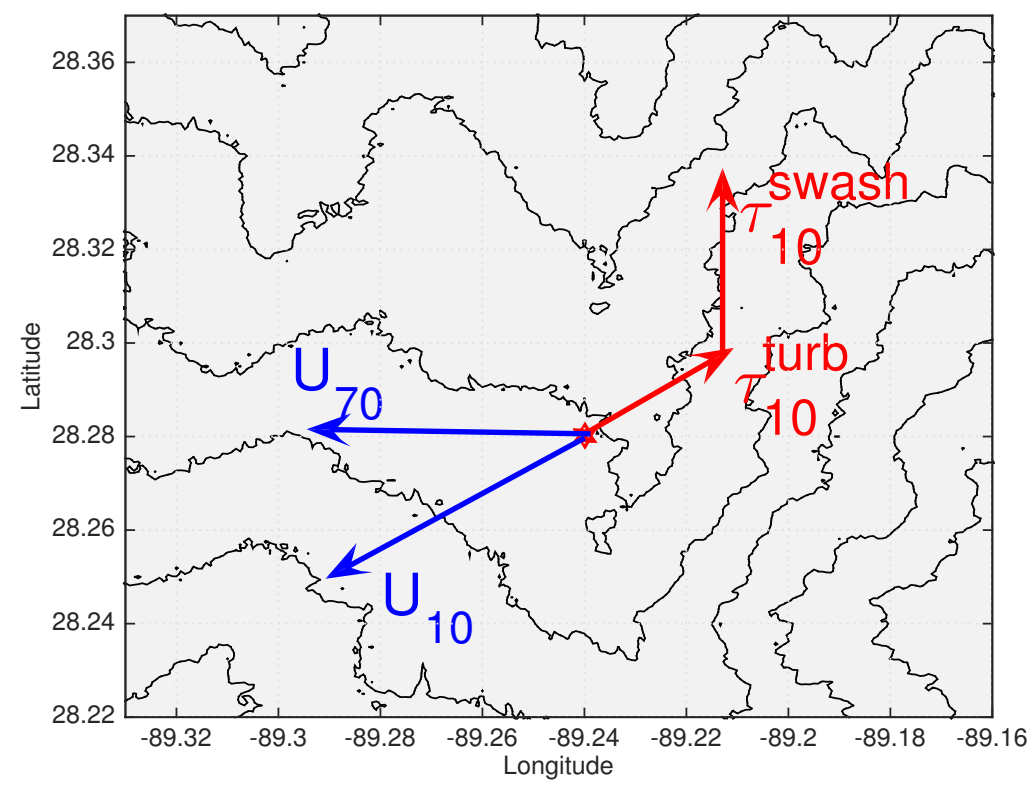

Figure 17. Horizontal velocity vectors at 10 and $70 \mathrm{~m} H_{\mathrm{ab}}$ (blues, $U_{10}$ and $U_{70}$ ) and vertical stress estimates (reds) at $10 \mathrm{~m} H_{\mathrm{ab}}$. The mooring location at $825 \mathrm{~m}$ water depth serves as the origin for the vectors and is denoted by a red pentagram. Bathymetry contours are at $50 \mathrm{~m}$ intervals. The stress vector is composed of turbulent contributions nearly antiparallel to the $10 \mathrm{~m}$ horizontal velocity $\left(\tau_{10}^{\text {turb }}\right)$ and a northward directed contribution from swash frequencies $\left(\tau_{10}^{\text {swash }}\right)$. 


\subsection{Temperature Fluxes}

Temperature measurements are collocated with velocity measurements by placing the sensing element of a standalone RBR Solo temperature recorder into the measurement volume of the MAVS. This enabled two lines of enquiry. The first is an estimate of what is commonly parsed as the partitioning of TKE production $\mathcal{P}$ into TKE dissipation $\epsilon$ and the dissipation of thermal variance $\chi$. We determined a dissipation ratio by inertial subrange arguments of $\Gamma_{\text {trans }}=0.14$, smaller than the commonly cited value of $\Gamma_{\mu}=0.2$. Although smaller, this implies a significant production of temperature variance. Decomposition of the temperature flux in the frequency domain provided a surprise. Estimates of production within the turbulent production band are negative, implying a restratification process in that frequency band. Production is contained within the internal swash band and dominated by frequencies of $(1-2) f$. This distribution of production and restratification within the internal wave band is similar to that documented by $[55,56]$.

\subsection{The Observed Fluxes vs. Atmospheric Surface Boundary Layer Measurements}

Comprehensive accounts of momentum and buoyancy fluxes in the atmospheric surface boundary layer can be found in textbooks $[53,57,58]$. Over flat topography, there are a few key parameters: wind speed, roughness length, and solar insolation that determine the boundary fluxes and their distribution in the vertical. A key piece is the Obukov height scale defined by the ratio of the buoyancy and momentum flux at the bottom boundary:

$$
L=\frac{-u_{*}^{3}}{k B}
$$

where $k=0.41$ is von Karmen's constant and B is the surface buoyancy flux. The Obukov height scale articulates the relative roles of stress and buoyancy. At values smaller than one, the boundary layer is considered stress driven. Negative values correspond to a positive buoyancy flux and convective situations. This length scale is used in the context of similarity scaling (Monin-Obukov similarity scaling) to collapse variability in flux profiles using a non-dimensional height scale $H_{\mathrm{ab}} / L$, in which we have inserted $H_{\mathrm{ab}}$ for the sensor height. The authors in [52] demonstrate how momentum and buoyancy flux cospectra evolve as a function of this non-dimensional height over a range of values $-2.0<H_{\mathrm{ab}} / L<2.0$. A key message from that study is that the buoyancy flux occurs at a slightly higher apparent frequency than the momentum flux: eddies with horizontal wavenumber smaller than $H_{\mathrm{ab}}$ transport buoyancy more efficiently than momentum. The lack of $w^{\prime} T^{\prime}$ covariance in the turbulent production regime stands in stark contrast to the atmospheric data. It is a statement about the importance of the internal swash phenomena to boundary mixing and our lack of understanding about the coupling of the internal wavefield with the bottom boundary layer. This assuredly has consequences for turbulent closure schemes such as [59] that need to be addressed. A way forward is to define a slope Obukov length scale by substituting the depth integrated cross-slope Ekman buoyancy transport for $B$, e.g., Ref. [29]. For our standard parameters, $H_{\mathrm{ab}} / L \cong-0.45$ If we had taken a drag coefficient half as large, $H_{\mathrm{ab}} / L \cong-0.9$.

\subsection{Speculation about the Ocean's Planetary Boundary Layer}

Below, we explore some consequences of our flux estimates, equating an appropriately scaled version of the temperature flux with a buoyancy flux and relating the $10 \mathrm{~m}$ current to the bed stress using a drag coefficient of 0.0025. The reader should review Section 3.4.2 as concerns the statistical reliability of the flux estimates and understand the speculative nature of this sub-section. 


\subsubsection{Ekman Balances}

Here, we attempt to interpret the $10 \mathrm{~m} \mathrm{H}_{\mathrm{ab}}$ temperature flux estimates in terms of Ekman dynamics and one-dimensional models of the bottom boundary layer over a planar slope [26]. The downslope Ekman transport is

$$
T_{\text {ekman }}=\frac{u_{*}^{2}}{f} \cos (\vartheta)
$$

with turning angle $\vartheta$. The mean temperature tendency equation in a Cartesian coordinate system is:

$$
\bar{\theta}_{t}+\bar{v} \partial_{y} \theta+\bar{w} \partial_{z} \theta+\partial_{z} \overline{w^{\prime} T^{\prime}}+\partial_{y} \overline{v^{\prime} T^{\prime}} \cong 0 .
$$

Integrating over the Ekman layer and taking the $10 \mathrm{~m}$ measurements as being representative of that integral provides the wherewithal for a scale assessment of the mean temperature balance. This suggests comparing

$$
T_{\text {ekman }} \frac{\partial \theta}{\partial y}: \overline{w^{\prime} T^{\prime}}+\overline{v^{\prime} T^{\prime} \alpha}
$$

Here, we invoke the one-dimensional result [26] that the upslope gradient $\theta_{\|}=\alpha \theta_{z}^{\text {ext }}$ and have equated $\theta_{\|}$with $\theta_{y}$. We find a plausible order of magnitude agreement between the left-hand side,

$$
T_{\text {ekman }} \alpha\left(\frac{\partial \theta}{\partial z}\right)_{e x t} \cong 1.2 \times 0.0025 / 64=5 \times 10^{-5}
$$

and, from the right-hand side,

$$
\overline{w^{\prime} T^{\prime}}=4 \times 10^{-5}
$$

with smaller contributions from

$$
\overline{v^{\prime} T^{\prime}} \alpha=7 \times 10^{-6}
$$

We are led to an appreciation that the downslope temperature advection is essentially balanced by swash band temperature fluxes. This is understood to be a general result in the context of the one-dimensional model: the residual between downslope advection and upslope fluxes gives rise to a smaller cross-isopycnal upwelling [60]. Whether these temperature fluxes result in local dissipation is a different question.

If we had taken a drag coefficient half as large, temperature transport in the Ekman layer would be four times smaller than the temperature flux.

\subsubsection{Production-Dissipation}

In a steady production-dissipation balance of the temperature variance equation,

$$
\left(\overline{v^{\prime} T^{\prime}}, \overline{w^{\prime} T^{\prime}}\right) \cdot\left(\theta_{y}, \theta_{z}\right)=-\chi / 2
$$

Our estimates of production $\left(1.4 \times 10^{-7} \quad \mathrm{C}^{2} \quad \mathrm{~s}^{-1}\right)$ and dissipation $\left(\chi / 2=2.6 \times 10^{-8} \mathrm{C}^{2} \mathrm{~s}^{-1}\right)$ differ by a factor of five, with production estimates in excess of dissipation. A fundamental concern is the contribution of nonlinear transport terms in the temperature variance budget (9) [38].

\subsubsection{Diapycnal Advection}

Since there is neither advection nor stirring of density along a surface of constant density, if one can ignore nonlinearities in the equation of state, one arrives at the remarkably simple balance [50,61]:

$$
\tilde{\mathbf{e}}=-\frac{\nabla \cdot \mathbf{F}_{\rho}}{\|\nabla \rho\|} \mathbf{n}_{\rho}
$$


in which $\tilde{\mathbf{e}}$ is the mean diapycnal velocity and $\mathbf{F}_{\rho}$ is the density flux. The factor $\mathbf{n}_{\rho}$ is a unit vector normal to the mean isopycnal surface and the gradient operators serve to pick out that part of the flux that is normal to the mean isopycnals.

This balance plays a central role in recent speculation about global ocean upwelling $[50,62,63]$, in which these authors all invoke a decreasing density flux magnitude with decreasing height above the bottom, starting at the top of the nominal boundary layer, despite observations that demonstrate high universal increase of dissipation with decreasing $H_{\mathrm{ab}}$. These arguments link diapycnal upwelling to the decreasing buoyancy flux magnitude within the bottom boundary layer.

The logic behind these arguments implicitly assumes that horizontal and vertical temperature fluxes have a similar order of magnitude and that balances in the temperature (buoyancy) variance Equation (9) are local (i.e., the nonlinear transport terms can be neglected) [42]. With such assumptions, the no-flux bottom boundary condition can be reduced to a requirement that the vertical buoyancy flux tends toward zero as the bottom is approached [50]. The data presented here demonstrate otherwise on both accounts: horizontal temperature fluxes dominate the vertical and call into question the implicit assumption of an isotropic closure. The swash band fluxes do not balance dissipation and suggest a potentially important role of the nonlinear transport terms in redistributing turbulence within the boundary layer.

An allure of arguments prescribing the vertical structure of the buoyancy flux within the boundary layer is the notion of potential length scale limitations in a stress driven turbulent field leading to reduced dissipation ratios. This seems a rather intuitive notion for boundary layer turbulence as the boundary is approached, but there is an equally intuitive notion to argue for precisely the opposite: the downwelling Ekman layer hosts a convective process and internal swash can be parsed as episodic convection with such intermittent convective events dominating the variance budgets. One anticipates $O(1)$ dissipation ratios to characterize convection, rather than values decreasing from a nominal $\Gamma_{\mu}=0.20$ to zero.

The fallacy [42] underlying these [50] upwelling arguments may originate in the fact that the no-flux bottom boundary condition controls the stratification only on scales smaller than the log-layer $[29,64]$, rather than the $\mathrm{O}(100) \mathrm{m}$ envisioned by those authors $[50,62,63]$. Clearly, further work needs to be done.

\subsection{Assessments}

In one-dimensional models of the downwelling Ekman layer [19,25,28,29], the downslope advection of buoyancy can result in convectively unstable conditions [65]. Information about the downslope buoyancy advection can be carried aloft to heights in excess of the penetration depth of the turbulent momentum flux by coupling with the internal wave mode at the slope frequency (Equation (6)), providing a time dependent response. The topography about the mooring contrasts sharply with the planar sloping boundary assumed by the one-dimensional models. The mooring was placed just in the lee of a topographic crest. We anticipate that there may be elements of downslope acceleration in response to pressure gradients across the topography, also referred to as form drag. This downslope acceleration could act to decrease the boundary layer height scale. The boundary layer height documented by the mooring $(10 \mathrm{~m})$ is slightly smaller than that in the CTD Tow-Yos about the mooring, Figure 8.

If we had taken a drag coefficient half as large as our standard parameter, there would be less disparity between the stratified Ekman layer height scale $\delta_{\text {strat }}$, now $14 \mathrm{~m}$, and that identified in the mooring $(10 \mathrm{~m})$ and quite similar to that in the Tow-Yo data. One could further argue that the appropriate scaling velocity in the farfield of the log layer (taken as $0.2 \mathrm{~m} \mathrm{~s}^{-1}$ ) should be reduced by a thermal wind contribution (a reduction of about $0.015 \mathrm{~m} \mathrm{~s}^{-1}$ ).

If we had taken a drag coefficient half as large as our standard parameter, the nominal veering angle associated with the Ekman layer would be a factor of four smaller than 
documented by the moored data. This could be compensated by asserting that the time mean velocity estimates contain a significant contribution from an upward propagating near-inertial wave phase locked to the topography, in addition to the obvious near-inertial time dependent response.

However, there is still something significant to explain: the stratified Ekman layer height scale ignores convective forcing related to cross-slope buoyancy transports which continue over a far longer time scale than required for the equilibration of the stratified Ekman layer over a flat bottom. This implies a ventilation or restratification process that keeps pace with the downslope advection driven by the bed stress. The temperature flux estimates locate this process in the internal swash band. If we had taken a drag coefficient half as large as our standard parameter, the internal swash band temperature fluxes would exceed the downslope Ekman temperature transport by a factor of four.

\subsection{Sensor Performance}

This study is based upon the use of a prototype sensor tested as part of a boundary mixing program on the northern continental slope of the Gulf of Mexico. As an instrument test, it suggests that there are no intrinsic limitations to using such flux sensors on conventional moorings. This opens up a world of exploration. Further improvements to the sensor package include:

- Recording serial output of an RBR Solo with MAVS to eliminate the potential for time base issues.

- Our implementation of the SBE-7/8 micro temperature and conductivity units was not successful, but our experience does not speak to conceptual issues.

- An alternate route to estimating a salinity flux is to utilize estimates of absolute travel time for speed of sound fluctuations [66] in combination with a direct temperature measurement.

- Motionally induced noise could be reduced by using faired cable.

- Developing a dynamical mooring model to understand how to avoid resonances that lead to large amplitude strumming.

- Increasing sampling rate by a factor of two or so would place aliased strumming induced noise into its natural frequency band.

- A longer sensing element for the temperature sensor would remove the instrument case from the vicinity of the MAVS sampling volume and reduce the potential for flow blockage.

- Any discussion of either turbulent or internal swash band momentum fluxes is referenced to the bed stress. Typically, one wants such a measurement near the top of the log-layer, less than one meter $H_{\mathrm{ab}}$. Due to the need for releases and some amount of chain to take up shock loading when the anchor hits bottom, the closest one can manage to place a sensor on a conventional mooring is roughly $6 \mathrm{~m} \mathrm{H} H_{\mathrm{ab}}$. Conventional moorings will likely need to be paired with bottom landers.

- a drawback of the VN100 motion package we employed is that it requires a $17 \mathrm{~s}$ boot time, which restricts sampling schemes.

Author Contributions: Conceptualization, K.L.P., A.J.W.III and Z.W.; methodology, K.L.P.; validation, K.L.P., B.W. and Z.W.; formal analysis, K.L.P.; investigation, K.L.P., F.T., A.J.W.III and B.W.; resources, K.L.P., F.T. and A.J.W.III; data curation, K.L.P., B.W. and Z.W.; writing-original draft preparation, K.L.P.; writing-review and editing, Z.W. and B.W.; visualization, K.L.P. and B.W.; supervision, K.L.P.; project administration, K.L.P.; funding acquisition, K.L.P. and Z.W. All authors have read and agreed to the published version of the manuscript.

Funding: Funding for GoMIX was provided by BP through the Gulf of Mexico Research Initiative (GoMRI), and is administered by the Consortium for Ocean Leadership. K.L.P., B.W., Z.W. and F.T. recognize funding from GoMIX/GoMRI contract \# SA12-09/GoMRI-006.

Data Availability Statement: The GoMIX data used in this study are available via the GoMRI GRIIDC data base (https: / / data.gulfresearchinitiative.org, accessed on 19 May 2021). 
Acknowledgments: The skill and cooperation of the masters and crew of R/V Pt. Sur, operated by the Louisiana Universities Marine Consortium (LUMCON), were essential to the success of the cruises from which the data reported herein were obtained.

Conflicts of Interest: One of us, Albert Williams, is a principal of Nobska Development, Inc. who provided the MAVS current meter used in obtaining some of these measurements. Modifications to the standard MAVS were made in support of the special needs for this and subsequent deployments, including SBE 7 and 8 sensor logging and subsequently incorporation of RBR temperature measurements but not logged internally in MAVS in this experiment. Other authors declare no conflict of interest.

\author{
Abbreviations \\ BBL Bottom Boundary Layer \\ TKE Turbulent Kinetic Energy \\ MAVS Modular Acoustic Velocity Sensor
}

The following abbreviations are used in this manuscript:

\title{
References
}

1. Gross, T.F.; Williams, A.J., III; Grant, W.D. Long-term in situ calculations of kinetic energy and Reynolds stress in a deep sea boundary layer. J. Geophys. Res. Oceans 1986, 91, 8461-8469. [CrossRef]

2. McPhee, M.G.; Smith, J.D. Measurements of the turbulent boundary layer under pack ice. J. Phys. Oceanogr. 1976, 6, 696-711. [CrossRef]

3. Thwaites, F.; Williams, A. Development of a modular acoustic velocity sensor. In Proceedings of the OCEANS 96 MTS/IEEE Conference Proceedings, The Coastal Ocean-Prospects for the 21st Century, Fort Lauderdale, FL, USA, 23-26 September 1996; Volume 2, pp. 607-612.

4. Joye, S.B. Deepwater Horizon, 5 years on. Science 2015, 349, 592-593. [CrossRef]

5. Gros, J.; Socolofsky, S.A.; Dissanayake, A.L.; Jun, I.; Zhao, L.; Boufadel, M.C.; Reddy, C.M.; Arey, J.S. Petroleum dynamics in the sea and influence of subsea dispersant injection during Deepwater Horizon. Proc. Natl. Acad. Sci. USA 2017, 114, 10065-10070. [CrossRef] [PubMed]

6. McNutt, M.K.; Camilli, R.; Crone, T.J.; Guthrie, G.D.; Hsieh, P.A.; Ryerson, T.B.; Savas, O.; Shaffer, F. Review of flow rate estimates of the Deepwater Horizon oil spill. Proc. Natl. Acad. Sci. USA 2012, 109, 20260-20267. [CrossRef] [PubMed]

7. Socolofsky, S.A.; Adams, E.E.; Sherwood, C.R. Formation dynamics of subsurface hydrocarbon intrusions following the Deepwater Horizon blowout. Geophys. Res. Lett. 2011, 38. [CrossRef]

8. Ledwell, J.R.; He, R.; Xue, Z.; DiMarco, S.F.; Spencer, L.J.; Chapman, P. Dispersion of a tracer in the deep Gulf of Mexico. J. Geophys. Res. Oceans 2016, 121, 1110-1132. [CrossRef]

9. Kantha, L. Barotropic tides in the Gulf of Mexico. Wash. DC Am. Geophys. Union Geophys. Monogr. Ser. 2005, 161, 159-163.

10. Polzin, K.; Toole, J.; Ledwell, J.; Schmitt, R. Spatial variability of turbulent mixing in the abyssal ocean. Science 1997, $276,93-96$. [CrossRef]

11. Polzin, K.L. An abyssal recipe. Ocean Model. 2009, 30, 298-309. [CrossRef]

12. Zhang, X.; DiMarco, S.F.; Smith, D.C., IV; Howard, M.K.; Jochens, A.E.; Hetland, R.D. Near-resonant ocean response to sea breeze on a stratified continental shelf. J. Phys. Oceanogr. 2009, 39, 2137-2155. [CrossRef]

13. Zhang, X.; Smith, D.C., IV; DiMarco, S.F.; Hetland, R.D. A numerical study of sea-breeze-driven ocean Poincare wave propagation and mixing near the critical latitude. J. Phys. Oceanogr. 2010, 40, 48-66. [CrossRef]

14. Hamilton, P.; Lugo-Fernandez, A. Observations of high speed deep currents in the northern Gulf of Mexico. Geophys. Res. Lett. 2001, 28, 2867-2870. [CrossRef]

15. Oey, L.; Lee, H. Deep eddy energy and topographic Rossby waves in the Gulf of Mexico. J. Phys. Oceanogr. 2002, 32, 3499-3527. [CrossRef]

16. Hamilton, P. Topographic Rossby waves in the Gulf of Mexico. Prog. Oceanogr. 2009, 82, 1-31. [CrossRef]

17. Spencer, L.J.; DiMarco, S.F.; Wang, Z.; Kuehl, J.J.; Brooks, D.A. Asymmetric oceanic response to a hurricane: Deep water observations during Hurricane Isaac. J. Geophys. Res. Oceans 2016, 121, 7619-7649. [CrossRef]

18. Taylor, J.R.; Sarkar, S. Stratification effects in a bottom Ekman layer. J. Phys. Oceanogr. 2008, 38, 2535-2555. [CrossRef]

19. Weatherly, G.L.; Martin, P.J. On the structure and dynamics of the oceanic bottom boundary layer. J. Phys. Oceanogr. 1978, 8, 557-570. [CrossRef]

20. Zilitinkevich, S.; Esau, I. On integral measures of the neutral barotropic planetary boundary layer. Bound. Layer Meteorol. 2002, 104, 371-379. [CrossRef]

21. Zilitinkevich, S.; Baklanov, A. Calculation of the height of the stable boundary layer in practical applications. Bound. Layer Meteorol. 2002, 105, 389-409. [CrossRef] 
22. Perlin, A.; Moum, J.; Klymak, J.; Levine, M.; Boyd, T.; Kosro, P. Organization of stratification, turbulence, and veering in bottom Ekman layers. J. Geophys. Res. Oceans 2007, 112. [CrossRef]

23. Caldwell, D.; Van Atta, C.; Helland, K. A laboratory study of the turbulent Ekman layer. Geophys. Fluid Dyn. 1972, 3, 125-160. [CrossRef]

24. Pollard, R.T.; Rhines, P.B.; Thompson, R.O. The deepening of the wind-mixed layer. Geophys. Fluid Dyn. 1973, 4, 381-404. [CrossRef]

25. Brink, K.H.; Lentz, S.J. Buoyancy arrest and bottom Ekman transport. Part I: Steady flow. J. Phys. Oceanogr. 2010, 40, 621-635. [CrossRef]

26. Garrett, C.; MacCready, P.; Rhines, P. Boundary mixing and arrested Ekman layers: Rotating stratified flow near a sloping boundary. Annu. Rev. Fluid Mech. 1993, 25, 291-323. [CrossRef]

27. Trowbridge, J.; Lentz, S. Asymmetric behavior of an oceanic boundary layer above a sloping bottom. J. Phys. Oceanogr. 1991, 21, 1171-1185. [CrossRef]

28. Umlauf, L.; Smyth, W.D.; Moum, J.N. Energetics of bottom Ekman layers during buoyancy arrest. J. Phys. Oceanogr. 2015, 45, 3099-3117. [CrossRef]

29. Ruan, X.; Thompson, A.F.; Taylor, J.R. The Evolution and Arrest of a Turbulent Stratified Oceanic Bottom Boundary Layer over a Slope: Downslope Regime. J. Phys. Oceanogr. 2019, 49, 469-487. [CrossRef]

30. Bretherton, F.P. Momentum transport by gravity waves. Q. J. R. Meteorol. Soc. 1969, 95, 213-243. [CrossRef]

31. Baines, P.G. Topographic Effects in Stratified Flows; Cambridge University Press: Cambridge, UK, 1997.

32. Thorpe, S.A. The generation of internal waves by flow over the rough topography of a continental slope. Proc. R. Soc. Lond. Ser. A Math. Phys. Sci. 1992, 439, 115-130.

33. Leaman, K.D.; Sanford, T.B. Vertical energy propagation of inertial waves: A vector spectral analysis of velocity profiles. J. Geophys. Res. 1975, 80, 1975-1978. [CrossRef]

34. Benthuysen, J.; Thomas, L.N. Friction and diapycnal mixing at a slope: Boundary control of potential vorticity. J. Phys. Oceanogr. 2012, 42, 1509-1523. [CrossRef]

35. Hoskins, B. The role of potential vorticity in symmetric stability and instability. Q. J. R. Meteorol. Soc. 1974, 100, 480-482. [CrossRef]

36. Allen, J.; Newberger, P. On symmetric instabilities in oceanic bottom boundary layers. J. Phys. Oceanogr. 1998, 28, 1131-1151. [CrossRef]

37. Trivett, D.; Terray, E.; Williams, A. Error analysis of an acoustic current meter. IEEE J. Ocean. Eng. 1991, 16, 329-337. [CrossRef]

38. Shaw, W.J.; Trowbridge, J.H.; Williams, A.J., III. Budgets of turbulent kinetic energy and scalar variance in the continental shelf bottom boundary layer. J. Geophys. Res. Oceans 2001, 106, 9551-9564. [CrossRef]

39. Horne, E.P.W.; Toole, J.M. Sensor response mismatches and lag correction techniques for temperature-salinity profilers. J. Phys. Oceanogr. 1980, 10, 1122-1130. [CrossRef]

40. Gregg, M.; D’Asaro, E.; Riley, J.; Kunze, E. Mixing Efficiency in the Ocean. Annu. Rev. Mar. Sci. 2018, 10, 443-473. [CrossRef]

41. Osborn, T.R.; Cox, C.S. Oceanic fine structure. Geophys. Fluid Dyn. 1972, 3, 321-345. [CrossRef]

42. Polzin, K.L.; McDougal, T. Mixing at the Ocean's Bottom Boundary. In Ocean Mixing; Meredith, M., Naveira Garabato, A., Eds.; Elsevier: Amsterdam, The Netherlands, 2021.

43. Kolmogorov, A.N. The local structure of turbulence in incompressible viscous fluid for very large Reynolds numbers. CR Acad. Sci. URSS 1941, 30, 301-305.

44. Sreenivasan, K.R. On the universality of the Kolmogorov constant. Phys. Fluids 1995, 7, 2778-2784. [CrossRef]

45. Gargett, A.; Osborn, T.; Nasmyth, P. Local isotropy and the decay of turbulence in a stratified fluid. J. Fluid Mech. 1984, 144, 231-280. [CrossRef]

46. Sreenivasan, K.R. The passive scalar spectrum and the Obukhov-Corrsin constant. Phys. Fluids 1996, 8, 189-196. [CrossRef]

47. Bouruet-Aubertot, P.; Van Haren, H.; Lelong, M.P. Stratified inertial subrange inferred from in situ measurements in the bottom boundary layer of the Rockall channel. J. Phys. Oceanogr. 2010, 40, 2401-2417. [CrossRef]

48. Slinn, D.N.; Riley, J. A model for the simulation of turbulent boundary layers in an incompressible stratified flow. J. Comput. Phys. 1998, 144, 550-602. [CrossRef]

49. Sarkar, S.; Scotti, A. From topographic internal gravity waves to turbulence. Annu. Rev. Fluid Mech. 2017, 49, 195-220. [CrossRef]

50. Ferrari, R.; Mashayek, A.; McDougall, T.J.; Nikurashin, M.; Campin, J.M. Turning Ocean Mixing Upside Down. J. Phys. Oceanogr. 2016, 46, 2239-2261. [CrossRef]

51. Holleman, R.C.; Geyer, W.R.; Ralston, D.K. Stratified Turbulence and Mixing Efficiency in a Salt Wedge Estuary. J. Phys. Oceanogr. 2016, 46, 1769-1783. [CrossRef]

52. Kaimal, J.; Wyngaard, J.; Izumi, Y.; Cote, O. Spectral characteristics of surface-layer turbulence. Q. J. R. Meteorol. Soc. 1972, 98, 563-589. [CrossRef]

53. Kaimal, J.C.; Finnigan, J.J. Atmospheric Boundary Layer Flows: Their Structure and Measurement; Oxford University Press: New York, NY, USA, 1994.

54. Thomas, L.N. On the effects of frontogenetic strain on symmetric instability and inertia-gravity waves. J. Fluid Mech. 2012, 711, 620. [CrossRef]

55. van Haren, H.; Oakey, N.; Garrett, C. Measurements of internal wave band eddy fluxes above a sloping bottom. J. Mar. Res. 1994, 52, 909-946. [CrossRef] 
56. Gemmrich, J.R.; van Haren, H. Internal wave band eddy fluxes above a continental slope. J. Mar. Res. 2002, 60, 227-253. [CrossRef]

57. Stull, R.B. An Introduction to Boundary Layer Meteorology; Springer Science \& Business Media: New York, NY, USA, 2012 ; Volume 13.

58. Garratt, J.R. The atmospheric boundary layer. Earth Sci. Rev. 1994, 37, 89-134. [CrossRef]

59. Mellor, G.L.; Yamada, T. A hierarchy of turbulence closure models for planetary boundary layers. J. Atmos. Sci. 1974, 31, 1791-1806. [CrossRef]

60. Garrett, C. An isopycnal view of near-boundary mixing and associated flows. J. Phys. Oceanogr. 2001, 31, 138-142. [CrossRef]

61. McDougall, T.J. Dianeutral advection. In Parameterization of Small-Scale Processes: Proc. 'Aha Huliko' a Hawaiian Winter Workshop; Hawaii Institute of Geophysics Special Publication: Honolulu, HI, USA, 1989; pp. 289-315.

62. de Lavergne, C.; Madec, G.; Le Sommer, J.; Nurser, A.G.; Naveira Garabato, A.C. On the consumption of Antarctic Bottom Water in the abyssal ocean. J. Phys. Oceanogr. 2016, 46, 635-661. [CrossRef]

63. McDougall, T.J.; Ferrari, R. Abyssal Upwelling and Downwelling Driven by Near-Boundary Mixing. J. Phys. Oceanogr. 2017, 47, 261-283. [CrossRef]

64. Kaiser, B.; Pratt, L.J. The transition to turbulence within internal tide boundary layers in the abyssal ocean. In Proceedings of the Ocean Sciences Meeting 2020, San Diego, CA, USA, 16-21 February 2020.

65. Moum, J.; Perlin, A.; Klymak, J.; Levine, M.; Boyd, T.; Kosro, P. Convectively driven mixing in the bottom boundary layer. J. Phys. Oceanogr. 2004, 34, 2189-2202. [CrossRef]

66. Shaw, W.J.; Williams, A.J.; Trowbridge, J.H. Measurement of turbulent sound speed fluctuations with an acoustic travel-time meter. In Proceedings of the OCEANS 96 MTS/IEEE Conference Proceedings, The Coastal Ocean-Prospects for the 21st Century, Fort Lauderdale, FL, USA, 23-26 September 1996; pp. 105-110. 